\title{
Spatial and temporal variability in MLT turbulence inferred from in situ and ground-based observations during the WADIS-1 sounding rocket campaign
}

\author{
Boris Strelnikov $^{1}$, Artur Szewczyk ${ }^{1}$, Irina Strelnikova ${ }^{1}$, Ralph Latteck ${ }^{1}$, Gerd Baumgarten ${ }^{1}$, Franz-Josef Lübken ${ }^{1}$, \\ Markus Rapp ${ }^{2,8}$, Stefanos Fasoulas ${ }^{3}$, Stefan Löhle ${ }^{3}$, Martin Eberhart ${ }^{3}$, Ulf-Peter Hoppe ${ }^{4}$ Tim Dunker $^{4}$, \\ Martin Friedrich $^{5}$, Jonas Hedin ${ }^{6}$, Mikhail Khaplanov ${ }^{6, \dagger}$, Jörg Gumbel ${ }^{6}$, and Aroh Barjatya ${ }^{7}$ \\ ${ }^{1}$ Leibniz Institute of Atmospheric Physics at the Rostock University, Kühlungsborn, Germany \\ ${ }^{2}$ Deutsches Zentrum für Luft- und Raumfahrt, Institut für Physik der Atmosphäre, Oberpfaffenhofen, Germany \\ ${ }^{3}$ University of Stuttgart, Institute of Space Systems, Stuttgart, Germany \\ ${ }^{4}$ Department of Physics and Technology, University of Troms $\emptyset$ - The Arctic University of Norway, Troms $\emptyset$, Norway \\ ${ }^{5}$ Graz University of Technology, Graz, Austria \\ ${ }^{6}$ Department of Meteorology (MISU), Stockholm University, Stockholm, Sweden \\ ${ }^{7}$ Embry-Riddle Aeronautical University, Daytona Beach, FL, USA \\ ${ }^{8}$ Meteorologisches Institut München, Ludwig-Maximilian-Universität München, Munich, Germany \\ $\dagger$ deceased
}

Correspondence to: Boris Strelnikov (strelnikov@iap-kborn.de)

Received: 9 January 2017 - Revised: 14 March 2017 - Accepted: 20 March 2017 - Published: 10 April 2017

\begin{abstract}
In summer 2013 the WADIS-1 sounding rocket campaign was conducted at the Andøya Space Center (ACS) in northern Norway $\left(69^{\circ} \mathrm{N}, 16^{\circ} \mathrm{E}\right)$. Among other things, it addressed the question of the variability in mesosphere/lower thermosphere (MLT) turbulence, both in time and space. A unique feature of the WADIS project was multi-point turbulence sounding applying different measurement techniques including rocket-borne ionization gauges, VHF MAARSY radar, and VHF EISCAT radar near Troms $\varnothing$. This allowed for horizontal variability to be observed in the turbulence field in the MLT at scales from a few to $100 \mathrm{~km}$. We found that the turbulence dissipation rate, $\varepsilon$ varied in space in a wavelike manner both horizontally and in the vertical direction. This wavelike modulation reveals the same vertical wavelengths as those seen in gravity waves. We also found that the vertical mean value of radar observations of $\varepsilon$ agrees reasonably with rocket-borne measurements. In this way defined $\left\langle\varepsilon_{\text {radar }}\right\rangle$ value reveals clear tidal modulation and results in variation by up to 2 orders of magnitude with periods of $24 \mathrm{~h}$. The $\left\langle\varepsilon_{\text {radar }}\right\rangle$ value also shows $12 \mathrm{~h}$ and shorter (1 to a few hours) modulations resulting in one decade of variation in $\left\langle\varepsilon_{\text {radar }}\right\rangle$ magnitude. The $24 \mathrm{~h}$ modulation appeared to be in phase
\end{abstract}

with tidal change of horizontal wind observed by SAURAMF radar. Such wavelike and, in particular, tidal modulation of the turbulence dissipation field in the MLT region inferred from our analysis is a new finding of this work.

Keywords. Meteorology and atmospheric dynamics (turbulence)

\section{Introduction}

Since the pioneering work of Lindzen (1981) followed by modeling efforts (see, e.g., Holton, 1982; Fritts and Alexander, 2003; Eckermann et al., 2015b, a) and experimental evidences (e.g., Goldberg et al., 2004, 2006; Rapp et al., 2004), it is now understood that the thermal structure and circulation pattern of the mesosphere/lower thermosphere (MLT) region is essentially determined by dynamic processes. The latter include gravity waves, tides, their interaction with each other and with the background atmosphere, generally summarized by terms wave-wave and wave-mean flow interaction. Another important aspect of the MLT dynamics is turbulence generation by wave breakdown and wind shears. It 
is, in particular, well known that the dynamics drive summer mesopause region about $80 \mathrm{~K}$ below radiative equilibrium temperature (e.g., Becker and Schmitz, 2003), giving rise to formation of ice particles and, ultimately, to such phenomena as polar mesosphere summer echoes (PMSEs) and noctilucent clouds (NLCs) (e.g., Rapp and Lübken, 2004).

The resulting thermal structure directly influences the atmospheric chemistry, which, in turn, gives its feedback to the temperature field. That is, there are several exothermic reactions (mainly with odd oxygen) which do heat the atmosphere at rates of several tens of kelvin per day (e.g., Mlynczak and Solomon, 1991; Mlynczak, 1996; Formichev, 2009). Another competitive heat source in the MLT region is neutral air turbulence generated in situ by wave breaking and wind shears. Lübken et al. (2002) have shown that turbulent heating rates in the polar summer mesopause region are on average in the range of $10 \mathrm{~K} \mathrm{~d}^{-1}$, which is on the same order of magnitude as the chemical heat input.

Although many physical mechanisms driving the atmospheric dynamics are qualitatively understood, their quantitative input to global or local atmospheric system is poorly known. This lack of knowledge is circumvented in models by tuning them to achieve a somewhat better agreement with observations of the resulting temperature and/or wind fields.

Our knowledge of properties of the MLT turbulence is still very limited. The main reason for this lack of knowledge is difficulty of experimental research in the MLT. It is, for example, known from radar observations of PMSEs, whose existence indicates the presence of turbulence (whether active or fossil), that MLT turbulence is a mesoscale phenomenon (e.g., Rapp and Lübken, 2004). On the other hand, it is also known that turbulence is highly intermittent in both space and time (e.g., Fritts et al., 2009a, b, 2015; Achatz, 2005). However, the degree of this intermittency is not yet quantified by measurements. To reproduce realistic circulation patterns, models need to set up an integral effect of turbulence which can only be inferred from experimental studies. Mostly, the MLT turbulence variability studies address seasonal changes in the time domain (e.g., Lübken, 1997; Lübken et al., 2002) and latitudinal dependence in the spatial domain (e.g., Rapp et al., 2006). Turbulence variability at smaller scales is not yet quantified.

This paper shows results of experimental investigation of MLT turbulence in the frame of the WADIS sounding rocket mission. WADIS stands for WAve propagation and DISsipation in the middle atmosphere and, among other things, addresses the question of how variable the MLT turbulence is both in time and space. The paper is structured as follows. First, we give a short overview on turbulence measurements techniques applied in the MLT region. Then an introduction of the WADIS project and instrumentation is given. Next, in Sect. 5 the measurements results are shown followed by a deeper analysis of turbulence variability in Sect. 6. Finally, we discuss possible biases and uncertainties and summarize our findings.

\section{Turbulence measurement techniques}

MLT turbulence was studied experimentally applying both in situ and remote sensing techniques. In situ methods include mass spectrometers (e.g., von Zahn et al., 1990), electrostatic probes (e.g., Thrane and Grandal, 1981; Thrane et al., 1985; Blix et al., 1990a, b; Blix and Thrane, 1991), chemical release experiments (Larsen, 2002), and ionization gauges (Lübken, 1992, 1997; Lübken et al., 1993; Giebeler and Lübken, 1995). All these methods do not directly measure the velocity field but rather an effect of turbulence on different tracers. The currently most often applied techniques rely on ionization gauges, which measure relative fluctuations of neutral air density. The neutral density fluctuations seem to be to date the best tracer for MLT turbulence since they are passive, conservative, and precisely measurable with high time (spatial) resolution.

Remote sensing techniques for measurements of mesospheric turbulence are currently limited to radar observations which are based on measurements of backscatter from inhomogeneities of the refractive index of the atmosphere. The refractive index in the MLT is almost solely determined by electron density. It is assumed that the electron density variations in the lower ionosphere are caused by neutral air turbulence. Suitable reviews of radar turbulence measurements can be found in Hocking (1985) and Lübken (2014).

\subsection{In situ techniques}

High-resolution neutral air density measurements with the ionization gauges "TOTAL" (which stands for total number density, used in 1980-1992; Lübken, 1987; Hillert et al., 1994) and "CONE" ("Combined sensor for Neutrals and Electrons", which have been used since 1992; Giebeler et al., 1993) yield absolute densities of the atmosphere in the height range $70-110 \mathrm{~km}$ (Rapp et al., 2001). These instruments have an effective altitude resolution of $\sim 0.3 \mathrm{~m}$ for a typical rocket velocity of $1000 \mathrm{~m} \mathrm{~s}^{-1}$. CONE is sensitive to relatively small density fluctuations of as low as $0.05 \%$. These relative density fluctuations are used as a tracer (scalar) for turbulence. Its power spectral densities (PSDs) can be calculated by using either Fourier (Lübken, 1992) or wavelet analysis techniques (Strelnikov et al., 2003). Next, a onedimensional model spectrum for a turbulence tracer is fitted to the measured PSD yielding the turbulent energy dissipation rate, $\varepsilon$. The best known and most frequently used spectral models which have been adapted to neutral air density fluctuations are those by Heisenberg (1948), Tatarskii (1971), and Driscoll and Kennedy (1985). The last of these is better suited for tracers that have different viscosity to diffusivity ratio than the background media. For detailed description of the instruments, the analysis technique, and an overview of measurements conducted so far, the reader is referred to Strelnikov et al. (2013). 
Table 1. Radar system parameters.

\begin{tabular}{lrrrr}
\hline & MAARSY & EISCAT VHF & EISCAT UHF & SAURA \\
\hline Frequency $(\mathrm{MHz})$ & 53.5 & 224 & 930 & 3.17 \\
Wavelength $\lambda_{R}(\mathrm{~m})$ & 5.6 & 1.34 & 0.32 & 94.57 \\
Bragg wavelength $\lambda_{R} / 2(\mathrm{~m})$ & 2.8 & 0.67 & 0.16 & 47.29 \\
Bragg wave number $k=4 \pi / \lambda_{R}\left(\mathrm{~m}^{-1}\right)$ & 2.24 & 9.38 & 39.27 & 0.13 \\
Minimal range resolution $(\mathrm{m})$ & 50 & 300 & 300 & 1000 \\
Half-power full beam width $\theta\left(^{\circ}\right)$ & 3.6 & $1.5(1 \mathrm{klystron})$ & 0.5 & 6.4 \\
Transmitter peak power $(\mathrm{MW})$ & 0.8 & 46 & 2 & 0.116 \\
Antenna gain $(\mathrm{dBi})$ & 33.5 & 48.1 & 19.5 \\
Antenna geometry & Yagi & $120 \times 40 \mathrm{~m}_{\text {parabolic cylinder }}$ & $32 \mathrm{~m}$ parabolic & $2 \times 1 \mathrm{~km} \mathrm{cross}$ \\
Antenna area & $\sim 6300 \mathrm{~m}^{2}$ & $2400 \mathrm{~m}^{2}(1$ klystron $)$ & $804 \mathrm{~m}^{2}$ & \\
\hline
\end{tabular}

Table 2. Radar experiment parameters.

\begin{tabular}{|c|c|c|}
\hline & $\begin{array}{r}\text { MAARSY } \\
\text { vertical } \\
\text { beam }\end{array}$ & $\begin{array}{r}\text { EISCAT VHF } \\
\text { arc-dlayerv- } \\
\text { zenith }\end{array}$ \\
\hline Time resolution (s) & 163 & 5 \\
\hline Lag resolution (ms) & 25.6 & 1.35 \\
\hline Nyquist frequency (Hz) & 19.53 & 370 \\
\hline Nyquist frequency $\left(\mathrm{m} \mathrm{s}^{-1}\right)$ & 54.72 & 248 \\
\hline Spectral resolution $(\mathrm{Hz})$ & 0.038 & 2.9 \\
\hline Spectral resolution $\left(\mathrm{m} \mathrm{s}^{-1}\right)$ & 0.11 & 1.94 \\
\hline Ranges (km) & $50-115$ & $60-140$ \\
\hline Range resolution (km) & 0.3 & 0.3 \\
\hline
\end{tabular}

\subsection{Remote sensing techniques}

The radar turbulence measurement techniques are based on the assumption that the broadening of the Doppler spectrum is mainly caused by velocity fluctuations around a mean Doppler shift in the observational volume. If wind fluctuations are caused by a turbulent medium, this measured spectral width in velocity units can be uniquely related to the turbulent energy dissipation rate in the volume, $\varepsilon$ (see, e.g., Hocking, 1983, 1985; Lübken, 2014). Strelnikova and Rapp (2010) demonstrated that backscattering from PMSEs is a coherent scattering from turbulent structures and that observed spectral width in velocity units is a measure of energy dissipation rate independent of radar frequency. In this work we analyze PMSE measurements with two radars, the MAARSY (Middle Atmosphere ALOMAR Radar System) (Latteck et al., 2012) and the EISCAT (European Incoherent SCATter Scientific Association) radar near Troms $\varnothing$.

The main parameters of radars used in this study are summarized in Table 1. Particular experiment configurations used for turbulence measurements are compiled in Table 2.

\section{WADIS project}

The WADIS sounding rocket project was led by the Leibniz Institute of Atmospheric Physics (IAP) in Kühlungsborn, Germany, in partnership with the Institute of Space Systems (IRS) in Stuttgart and contributions from Austria, Sweden, the USA, and Norway. It comprised two field campaigns conducted at the Andøya Space Center (ACS) in northern Norway $\left(69^{\circ} \mathrm{N}, 16^{\circ} \mathrm{E}\right)$. The first campaign was conducted in June 2013 and the second in March 2015. The project title reads "Wave propagation and dissipation in the middle atmosphere: Energy budget and distribution of trace constituents". The mission aimed at studying the propagation of gravity waves (GWs) from their sources in the troposphere to their level of dissipation in the MLT and at quantifying their contribution to the energy budget of the MLT. The project also aimed to measure the concentration of atomic oxygen to estimate the contribution of radiation and chemical heating to the energy budget, as well as the transport of atomic oxygen by turbulent diffusion.

To characterize the GW properties the ALOMAR RMR lidar and Na Weber lidar were running continuously throughout the campaign period measuring temperature and horizontal wind in the height range from 20 to $\sim 100 \mathrm{~km}$ whenever weather permitted. Both the RMR and the Na lidar make use of two steerable telescopes. One of the telescopes was pointing towards the northwest to measure close to the predicted trajectory of the rocket, while the other measured in the opposite direction to facilitate wind measurements.

The SAURA MF radar and MAARSY operated by IAP are located close to the rocket launch site and are continuously running. The SAURA MF radar yields, among other things, long-term wind measurements enabling reliable analysis of long-period waves like tides (e.g., Hoffmann et al., 2008, 2010). MAARSY was used to detect mesospheric echoes, which, if present, allow for geophysical parameters to be derived, such as winds and turbulence energy dissipation rates (e.g., Rapp et al., 2011; Latteck et al., 2012). For the campaign period MAARSY was operated in a scanning mode using up to 69 different beam positions around zenith cover- 


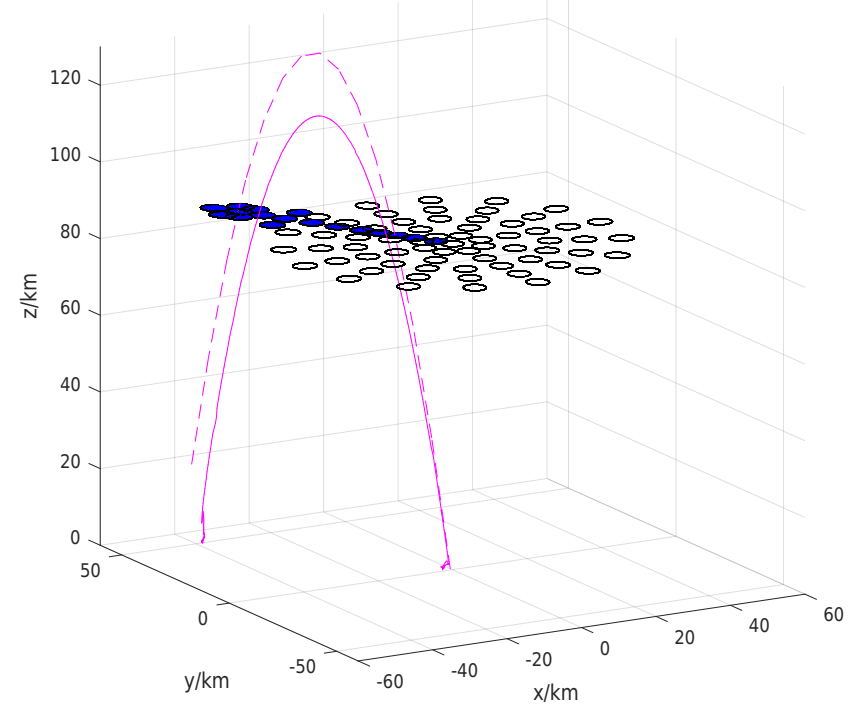

Figure 1. Geometry of MAARSY measurement setup. The circles show single beams' positions at $85 \mathrm{~km}$ altitude. Filled blue circles show 17 additional beam pointing directions for the WADIS-1 launch. The thin dashed magenta line shows the predicted rocket trajectory. The solid magenta line shows the actual rocket trajectory.

ing a horizontal area of about $80 \mathrm{~km}$ diameter at $85 \mathrm{~km}$ altitude. A vertical beam experiment covering the altitude range between 50.1 and $114.6 \mathrm{~km}$ with $150 \mathrm{~m}$ range resolution was followed by four experiments each pointing to 17 different oblique beam directions and towards zenith covering a range between 75.3 and $118.2 \mathrm{~km}$ with $300 \mathrm{~m}$ resolution. The circles in Fig. 1 indicate the areas at $85 \mathrm{~km}$ illuminated by these beams positions The experiment details relevant for the highresolution $(150 \mathrm{~m})$ vertical beam are listed in Table 2 . For the time of the rocket flight, 17 additional beam directions as indicated by the filled blue circles in Fig. 1 pointing towards the planned rocket trajectory (magenta dashed line) were included to the experiment sequence to provide spatially resolved information of PMSEs along the rocket trajectory. The maximum off-zenith angle used in this experiment was $37^{\circ}$.

In addition to the ALOMAR facilities, the WADIS-1 campaign also benefited from measurements with the EISCAT VHF and UHF radars in Troms $\varnothing$, which were running during the night of the WADIS-1 launch and thereby extended the observational area to approximately $100 \mathrm{~km}$ (Rapp et al., 2008).

The two WADIS campaigns comprised in total launches of 24 meteorological rockets carrying data sondes for wind measurements and two instrumented sounding rockets. A successful salvo of eight data sondes with other complementary launches allowed validation of wind measurements by the ALOMAR RMR lidar and is discussed in detail in Lübken et al. (2016).
Table 3. Rocket-borne instrumentation on WADIS-1 payload.

\begin{tabular}{|c|c|c|}
\hline Instrument & Parameter measured & Status \\
\hline CONE (NP) & neutral density & success \\
\hline CONE (EP) & electron density & failed \\
\hline PIP & positive ion density & success \\
\hline Wave prop. & abs. electron density & success \\
\hline \multirow[t]{2}{*}{ LP } & electron density & success \\
\hline & neutral aerosols & success \\
\hline FIPEX & oxygen density & success \\
\hline Photometers & oxygen density & success \\
\hline PD & charged aerosols & qualitative \\
\hline
\end{tabular}

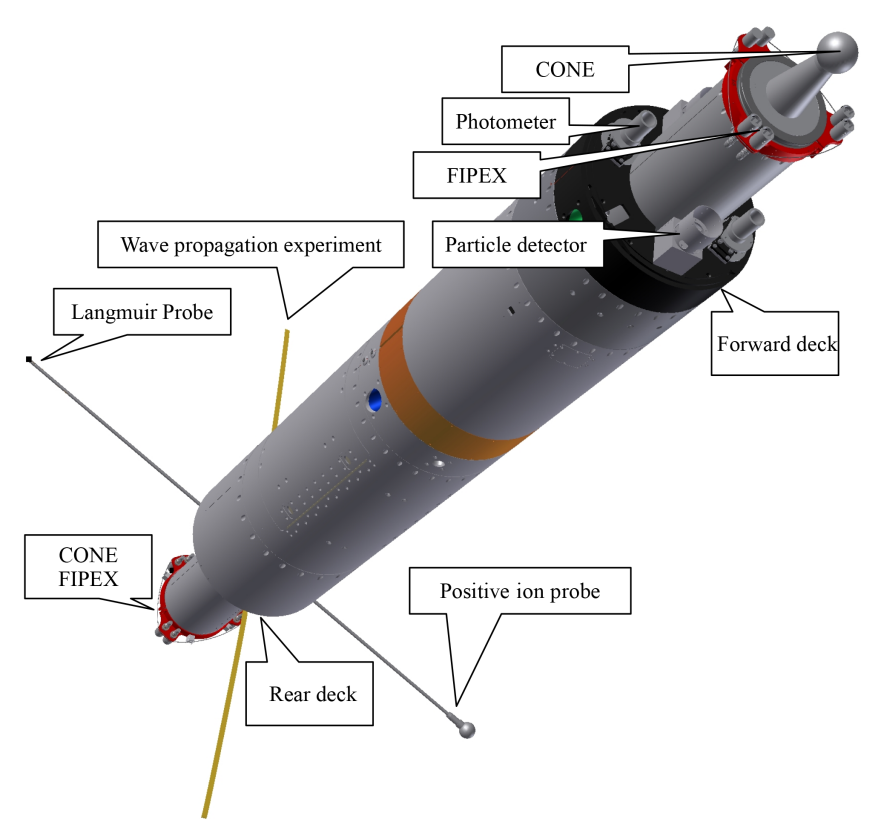

Figure 2. WADIS payload. See text for details.

\section{WADIS payload}

The instrumented WADIS payload was designed to gain two near-identical data sets on both up- and downleg of the rocket trajectory at a horizontal distance of a few tens of kilometers. Figure 2 shows the WADIS payload with the instrumentation exposed to the atmosphere.

The front and the rear decks of the WADIS payloads were equipped with identical CONE ionization gauges to measure turbulence and neutral air density. The latter also yields temperature measurements assuming hydrostatical equilibrium (Rapp et al., 2001).

The FIPEX instruments were developed by IRS and were for the first time ever flown on a sounding rocket during the WADIS- 1 campaign, yielding profiles of atomic oxygen densities with high altitude resolution (see Eberhart et al., 2015).

Photometers operated by Meteorological Institute at Stockholm University (MISU) measured oxygen densities 


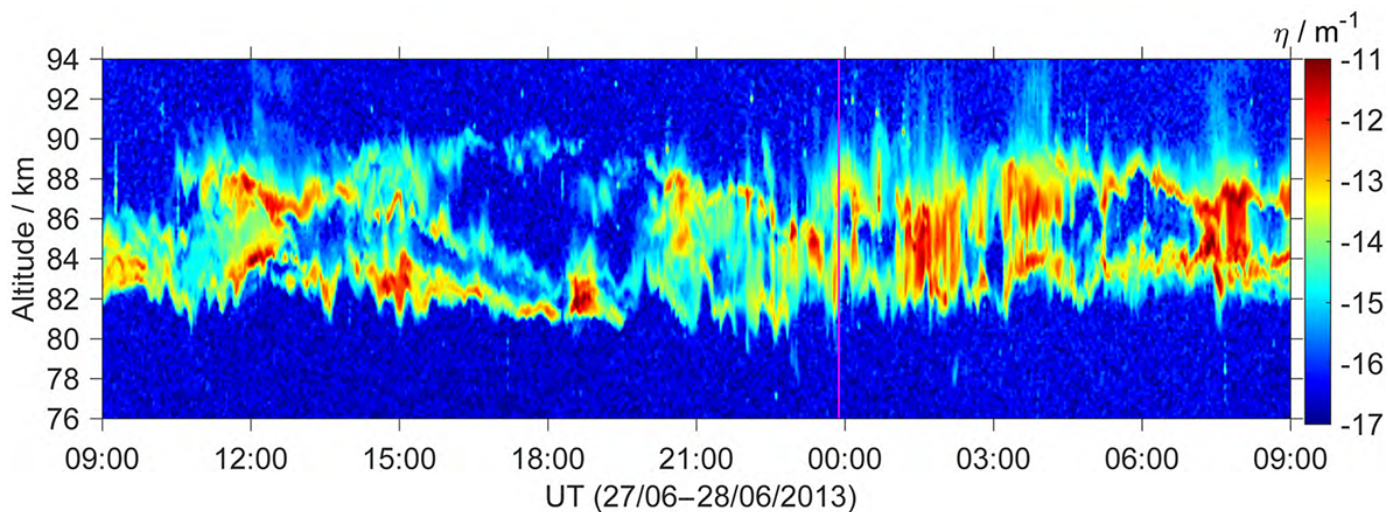

Figure 3. PMSE display observed by the vertical beam of MAARSY in terms of radar reflectivity. The vertical line marks the WADIS-1 launch time, 23:52:30 UTC.

using a well-established reliable technique applied before on a large number of sounding rockets (e.g., Hedin et al., 2009).

Both FIPEX and the photometers measured atomic oxygen densities, but utilizing different measurement techniques. The photometers yielded precise absolute density measurements, whereas FIPEX instruments supply high altitude resolution data. Also, the absolute values of the FIPEX measurements were validated by the photometers.

Ionospheric plasma densities were measured by a set of different probes, yielding relative densities of electrons (Langmuir probe and CONE), positive ions (by positive ion probe), and charged aerosols (by particle detector, PD), including their variations down to meter scales (e.g., Blix et al., 1990a). Absolute electron densities were precisely measured with the radio-wave propagation technique (Bennett et al., 1972; Jacobsen and Friedrich, 1979).

A novel Langmuir probe (LP) developed and operated by Embry-Riddle Aeronautical University in Florida, USA, not only yielded high-resolution electron density measurement, but also indicated the presence of heavier neutral aerosol particles.

Thus, the set of different plasma probes yielded density measurements of all the constituents of the E-region dusty plasma. Those measurements are beyond the scope of this study and will be discussed in detail in a forthcoming paper.

\section{Data}

In this paper we discuss measurement results obtained during the WADIS-1 sounding rocket campaign conducted in June 2013, focusing on turbulence measurements. We start with a description of launch conditions in the next section, followed by description of the background atmosphere, as inferred from our measurements. Then we show details of turbulence measurements by different techniques employed and discuss the results.

\subsection{Launch conditions}

The WADIS-1 payload was launched into both PMSEs observed with the MAARSY and NLCs monitored with the ALOMAR RMR lidar on 27 June at 23:52:30 UTC. The EISCAT VHF radar in Troms $\varnothing$ was also continuously detecting PMSEs during the entire night of the WADIS-1 launch. The EISCAT UHF radar observed PMSEs during the launch window, but these were only sporadic and very weak. Also, $\mathrm{Na}$ lidar observed a large sporadic $\mathrm{Na}$ layer several hours around the WADIS-1 launch.

Figure 3 shows a height-time intensity plot of radar volume reflectivity observed by the vertical beam of MAARSY. The volume reflectivity was converted directly from the absolute value of the received signal power as described in Latteck et al. (2008). The vertical magenta line marks the WADIS-1 launch time when MAARSY was detecting a double-layered structure. Figure 4 shows the signal-to-noise ratio detected by the MAARSY beams along the expected rocket trajectory shortly before launch time, indicating an extension of the double-layer structure towards the direction of the planned rocket flight.

Figure 5 shows NLC observations by the RMR lidar. The vertical dashed line marks the WADIS-1 launch and one can see that the NLC was co-located with the lower PMSE layer, which is a common feature (see e.g., von Zahn and Bremer, 1999; Lübken et al., 2004; She et al., 2006; Taylor et al., 2009; Robertson et al., 2009; Kaifler et al., 2011).

Figure 6 also shows EISCAT measurements in terms of radar reflectivity. One can see a prominent PMSE signature in the VHF data. Also, a double-layered structure similar to that observed by MAARSY is seen in the VHF display. The strong persistent signature in the UHF data appearing above $90 \mathrm{~km}$ heights is a sporadic E layer, i.e. a layer of enhanced electron density, which is also seen in the VHF measurements. The UHF PMSE is so weak that it cannot be identified on this volume reflectivity plot without special treatment. Yellow contours in the UHF plot mark regions where 


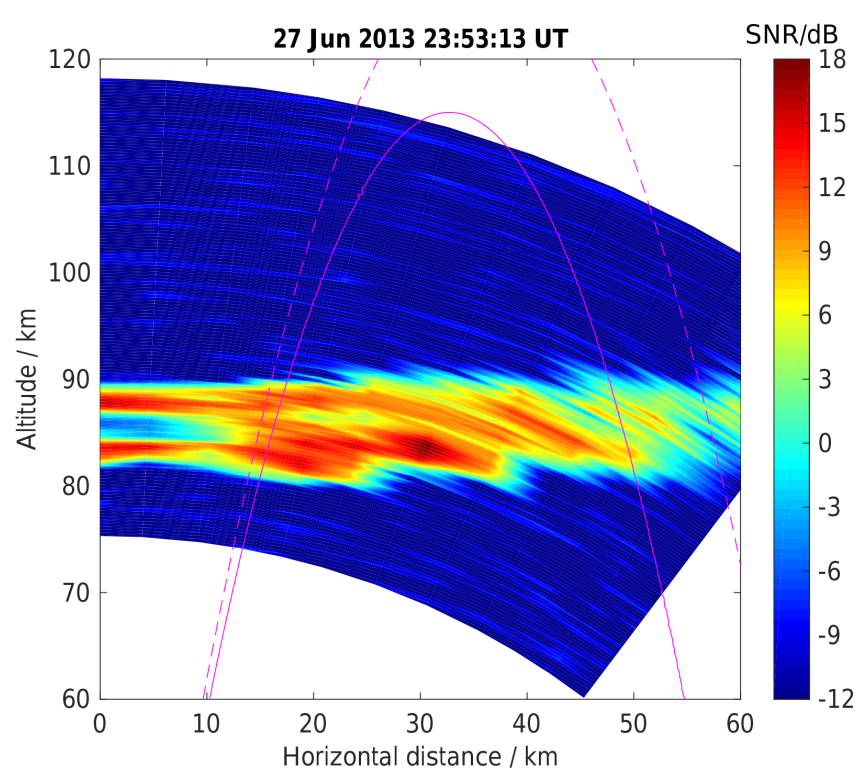

Figure 4. PMSE display observed by MAARSY along the rocket trajectory. Dashed and solid lines show predicted and actual trajectories, respectively.

the VHF radar observed PMSEs. The gap in the UHF data is because of some technical issues that briefly interrupted the radar operation during that night. Around the time of the WADIS-1 launch (23:52:30 UTC) both MAARSY and the EISCAT radars produced high-quality measurements, which we discuss in detail in the Sect. 6.

The persistent PMSE observations with the MAARSY and the EISCAT radars indicate that turbulence was occurring over an extended horizontal area in the mesopause region. We note, however, that PMSEs also occur during periods of fossil turbulence (Rapp and Lübken, 2003, 2004) such that the PMSE spectral width also needs to be evaluated in order to draw firm conclusions concerning the spatial extent of turbulence.

The rocket WADIS-1 was launched as vertically as possible based on launch safety requirements. The geometry of the measurements is sketched in Fig. 7.

The upleg and downleg measurements at a height of $\sim 80 \mathrm{~km}$ are separated horizontally by about $30 \mathrm{~km}$.

As stated above, one of the telescopes of the twin ALOMAR lidar system, i.e. of both RMR and Na lidars, was pointing to the direction of the anticipated rocket trajectory to achieve the best possible common-volume measurements. In the next section we discuss the measured parameters starting with the background state of the atmosphere.

\subsection{Background atmosphere}

The background wind field was continuously monitored with the SAURA-MF radar (Latteck et al., 2003; Singer et al., 2008). The zonal and meridional wind measurements around the WADIS-1 launch time are shown in Fig. 8. SAURA measurements reveal that between 80 and $90 \mathrm{~km}$ altitude mean horizontal wind was stably directed to the southwest several hours around the WADIS-1 launch time. The zonal wind shows a quite stable field, whereas the meridional component reveals a fluctuating behavior with prominent shears at $\sim 80$ and $90 \mathrm{~km}$.

Temperatures were continuously measured both by ALOMAR RMR and Na Weber lidars. The Na lidar additionally measured winds with relatively high temporal and spatial (vertical) resolution. The joint measurements by both lidars are shown in Fig. 9.

Also, as mentioned above, the RMR lidar was continuously observing NLCs throughout the entire night of the WADIS-1 launch, meaning that low temperatures below the frost point persisted in the corresponding altitude range of $80-90 \mathrm{~km}$ during that time.

The temperature was also measured in situ, applying the ionization gauge CONE. The corresponding temperature profiles are shown in Fig. 10 for up- and downleg in red and blue, respectively. The two temperature profiles measured with the Na and RMR lidars at the time of the rocket launch are shown in yellow and green, respectively. The black line shows temperature from the NRLMSISE-00 reference atmosphere (Picone et al., 2002). Pronounced wave signatures are seen in all temperature profiles above $\sim 80 \mathrm{~km}$. The difference of $\sim 30 \mathrm{~K}$ at heights of $85-90 \mathrm{~km}$ between temperatures measured on the up- and downleg can be attributed to gravity waves with a horizontal wavelength on the order of $60 \mathrm{~km}$ (twice the distance between the up- and downleg). Notably, between 90 and $95 \mathrm{~km}$ height the temperature reveals a very similar structure and very similar values in all profiles. This may be seen as an indication for a reduction of GW activity due to wave breakdown at heights of 80 to $90 \mathrm{~km}$; for a detailed discussion of this hypothesis see below.

It can be seen in Fig. 10 that the temperature profiles often exhibit near-adiabatic lapse rates. The in situ turbulence detection technique based on neutral density fluctuations measurements with CONE can be insensitive to turbulent layers where temperature gradient is adiabatic (e.g., Lehmacher et al., 2011). However, the plasma density fluctuations reveal positive vertical gradients in these regions and therefore can be used as a tracer for turbulence. The results of plasma density measurements during upleg of the WADIS-1 rocket flight are shown in Fig. 11. The high-resolution electron density measurements with the LP are shown by red line. It is seen that inside the NLC or lower PMSE layer the electron density profile exhibits a bite-out. This is a well-known and common feature (see, e.g., Friedrich et al., 2011; Li and Rapp, 2013, and references therein). Since the electron density in such a case is drastically affected by ice charging process, it cannot be considered as a passive tracer for turbulence, which prevents turbulence analysis from the electron density data inside PMSE layers. Note that beside the bite-out region, the LP yielded high-quality plasma density measurements. The 


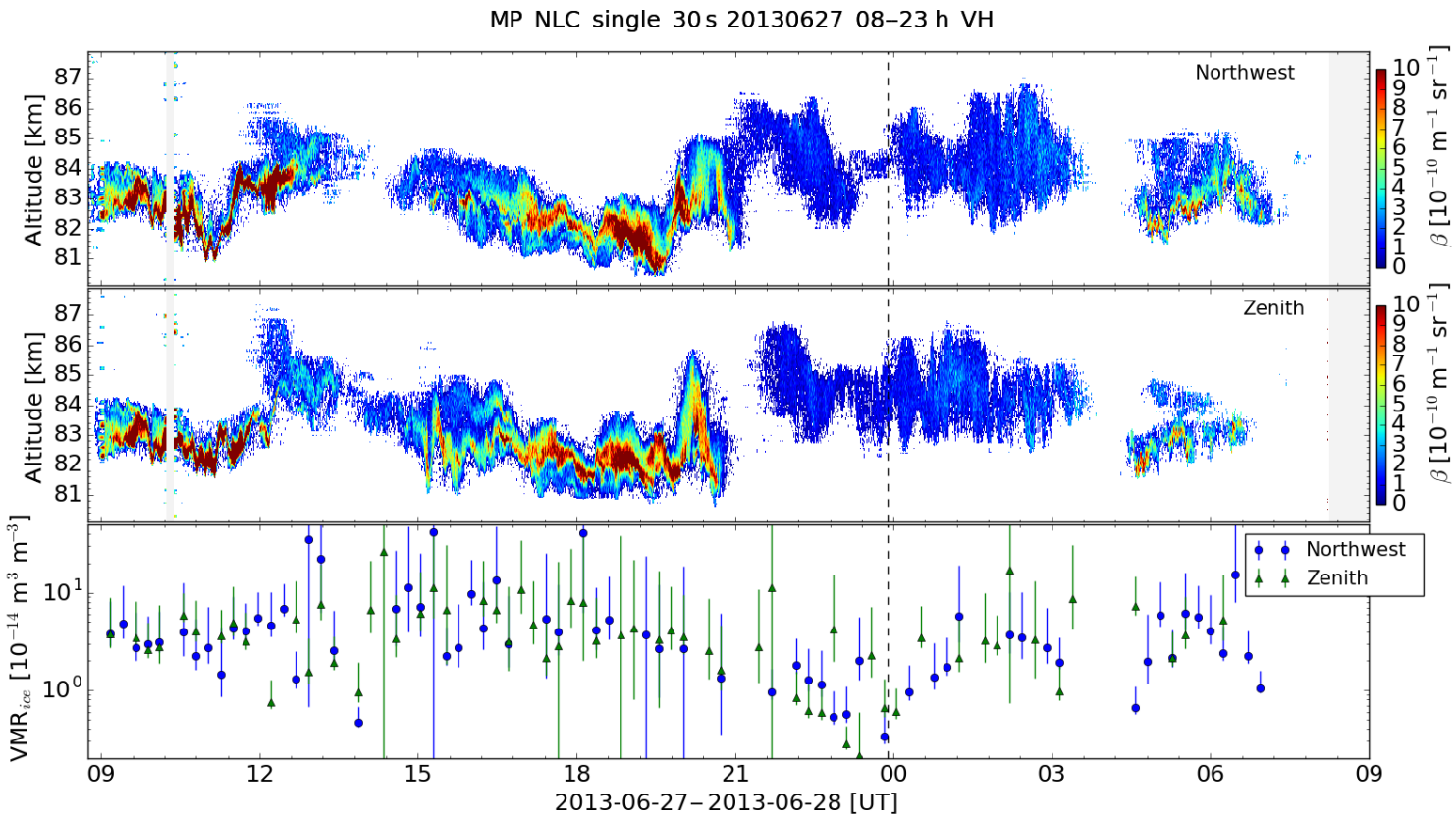

Figure 5. NLC observations by the RMR lidar. The vertical line marks the WADIS-1 launch.

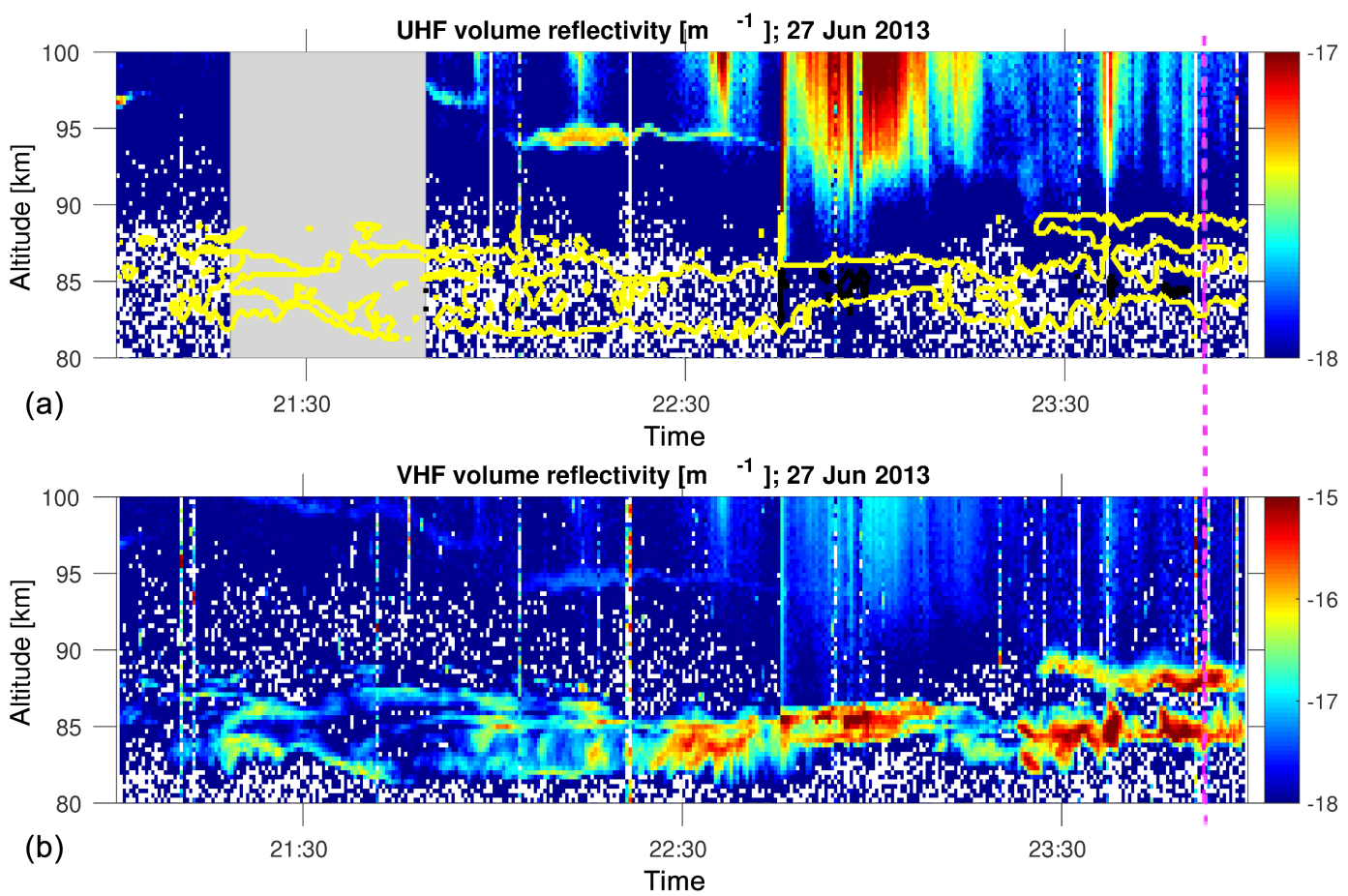

Figure 6. EISCAT measurements in terms of radar reflectivity. The upper and lower panel show UHF and VHF data, respectively. Yellow contours in the UHF plot mark regions where the VHF radar observed PMSEs. Note the different scales of the reflectivity.

ion density measurements were not sensitive enough to resolve full spectrum of turbulence needed for $\varepsilon$ derivation.

To summarize, the snapshot of the background temperature field in the mesopause region reveals a wealth of wave signatures in both vertical and horizontal extent. The relatively stable wind field between 80 and $90 \mathrm{~km}$ height suggests a dynamically stable atmosphere at these altitudes. Taken together this suggests that turbulence generation at these 


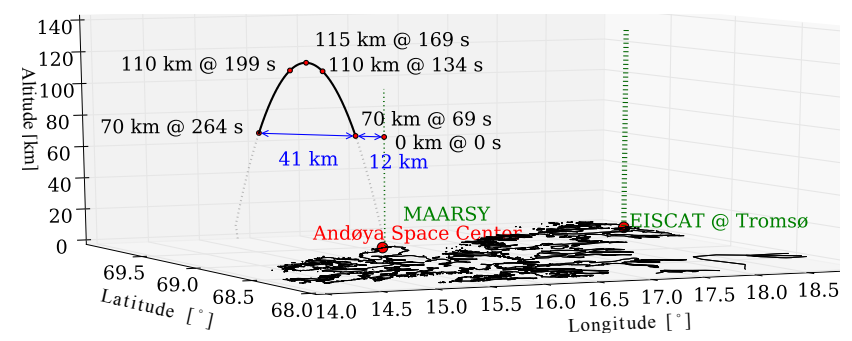

Figure 7. Geometry of in situ and ground-based measurements during WADIS-1 sounding rocket campaign.

heights may be attributed to GW breakdown processes. In the next sections we investigate the corresponding variation in the turbulent energy dissipation rate to see whether these are consistent with our hypothesis.

\subsection{Turbulence measurements}

Profiles of measured turbulence energy dissipation rates, $\varepsilon$, are compiled in Fig. 12. The blue and green lines show $\varepsilon$ values derived from the in situ measurements using Heisenberg (1948) and Tatarskii (1971) spectral models, respectively. It is seen that both models yield very close values and generally agree very well. The left and right panels show upleg and downleg measurements, respectively. The lines in magenta show energy dissipation rates derived from the vertical beam measurements with MAARSY during the time of the rocket ascent. The dark-red profile represents the results of turbulence estimates from the EISCAT VHF radar measurements, also during the time of the WADIS-1 launch. The solid gray and black lines show $\varepsilon$ climatologies derived from the same in situ technique for winter (Lübken, 1997) and summer (Lübken et al., 2002), respectively. The black dashed line shows low limit estimate for turbulence energy dissipation rate derived as $\varepsilon_{\min }=v \times \omega_{B}^{2}$, where $v$ is the kinematic viscosity of neutral air and $\omega_{B}$ is the Brunt-Väisälä frequency (see, e.g., Lehmacher et al., 2011; Strelnikov et al., 2013).

Between 82 and $90 \mathrm{~km}$ height both radars (MAARSY and EISCAT) and the sounding rocket detected two major turbulent layers, marked in Fig. 12 by the shaded areas. This is consistent with the PMSE display observed by MAARSY. The upper layer is located between 85 and $90 \mathrm{~km}$ and the lower between 82 and $85 \mathrm{~km}$ height. Here the rocket upleg measurements are noteworthy, which show turbulence layers between 82 and $70 \mathrm{~km}$ altitude, something rather unusual for summer conditions. Note that both the MAARSY and the EISCAT radar are only capable of measuring turbulence inside the PMSE layers that is between $\sim 80$ and $90 \mathrm{~km}$.

To better compare the in situ and radar turbulence measurements, we plotted mean energy dissipation rates derived between 80 and $90 \mathrm{~km}$ heights from the rocket-borne and radar measurements which are shown by vertical dashed lines. Note that the mean values compare well. The rocket upleg data were measured spatially close to the vertical MAARSY beam and the derived dissipation rates reveal close values: $\left\langle\varepsilon_{\text {upleg }}^{\text {Heisenberg }}\right\rangle=74 \mathrm{~mW} \mathrm{~kg}^{-1},\left\langle\varepsilon_{\text {upleg }}^{\text {Tatarskii }}\right\rangle=$ $73 \mathrm{~mW} \mathrm{~kg}^{-1},\left\langle\varepsilon^{\text {MAARSY }}\right\rangle=58 \mathrm{~mW} \mathrm{~kg}^{-1}$, where $\langle\ldots\rangle \mathrm{de}-$ notes spatial averaging over the height range $80-90 \mathrm{~km}$. The downleg rocket measurements reveal larger energy dissipation rates and the derived mean values are closer to those of the EISCAT radar, which was located $\sim 100 \mathrm{~km}$ east of the rocket launch site. The corresponding mean values are $\left\langle\varepsilon_{\text {downleg }}^{\text {Heisenberg }}\right\rangle=492 \mathrm{~mW} \mathrm{~kg}^{-1},\left\langle\varepsilon_{\text {downleg }}^{\text {Tatarskii }}\right\rangle=$ $307 \mathrm{~mW} \mathrm{~kg}^{-1}$, and $\left\langle\varepsilon^{\text {EISCAT }}\right\rangle=769 \mathrm{~mW} \mathrm{~kg}^{-1}$. Also, within the upper turbulent region the in situ downleg measurements show two pronounced sub-layers with very high $\varepsilon$ values. The lower one is found between 85.5 and $85.8 \mathrm{~km}$ that is only $300 \mathrm{~m}$ thick and reveals energy dissipation rates of up to $\sim 7 \mathrm{~mW} \mathrm{~kg}^{-1}$. The upper one appears between 87.2 and $87.8 \mathrm{~km}$ and shows $\varepsilon \approx 1 \mathrm{~mW} \mathrm{~kg}^{-1}$.

This indicates that the high $\varepsilon$ values, derived from the EISCAT measurements in this study or, for example, by Strelnikova and Rapp (2013) are likely realistic. Another important remark regarding these measurements is that the $\underline{\text { mean } \varepsilon \text { values differ from high-resolution instantaneous }}$ measurements by orders of magnitude. The latter must be kept in mind when comparing means and especially climatologies by Lübken (1997) and Lübken et al. (2002) with other measurements in the context of case studies.

Another characteristic feature seen in the in situ turbulence measurements is the large vertical gradients in the $\varepsilon$ profiles. Thus, for instance the downleg data between 85.0 and $85.5 \mathrm{~km}$ reveals an increase by 5 orders of magnitude in the turbulence dissipation rate value. Also, intermittency, i.e., the rapid change in $\varepsilon$ values on very short (down to $100 \mathrm{~m}$ ) vertical scales, and discontinuities in the $\varepsilon$ profiles are clearly seen in the in situ measurements. Such pronounced gradients and intermittency in the $\varepsilon$ profiles were previously observed by the same instrument (e.g., Strelnikov et al., 2003; Rapp et al., 2004) and also appear in direct numerical simulations (see, e.g., Fritts et al., 2009a, b, 2015) and seem to be an immanence of atmospheric turbulence.

Radars do not detect such very strong gradients, most probably because of the large measurement volume and the additional time averaging needed to achieve a reasonable signal-to-noise ratio (SNR). For example, the EISCAT VHF radar beam reveals $300 \mathrm{~m}$ vertical and $2300 \mathrm{~m}$ horizontal extent at $85 \mathrm{~km}$ height (e.g., Strelnikova and Rapp, 2011). The maximum vertical gradient of the $\varepsilon$ values observed by the EISCAT VHF during WADIS-1 campaign was $33 \mathrm{~mW} \mathrm{~kg}^{-1} \mathrm{~km}^{-1}$, whereas the maximum $\varepsilon$ gradient revealed by the in situ measurements is $\sim 44 \mathrm{~mW} \mathrm{~kg}^{-1} \mathrm{~km}^{-1}$. Though the $\varepsilon$ gradient value derived from the EISCAT observations is slightly lower than those from the rocket-borne measurements, the values are still remarkably close to each other. This further supports the reliability of the EISCAT turbulence measurements. Unfortunately, the EISCAT measure- 


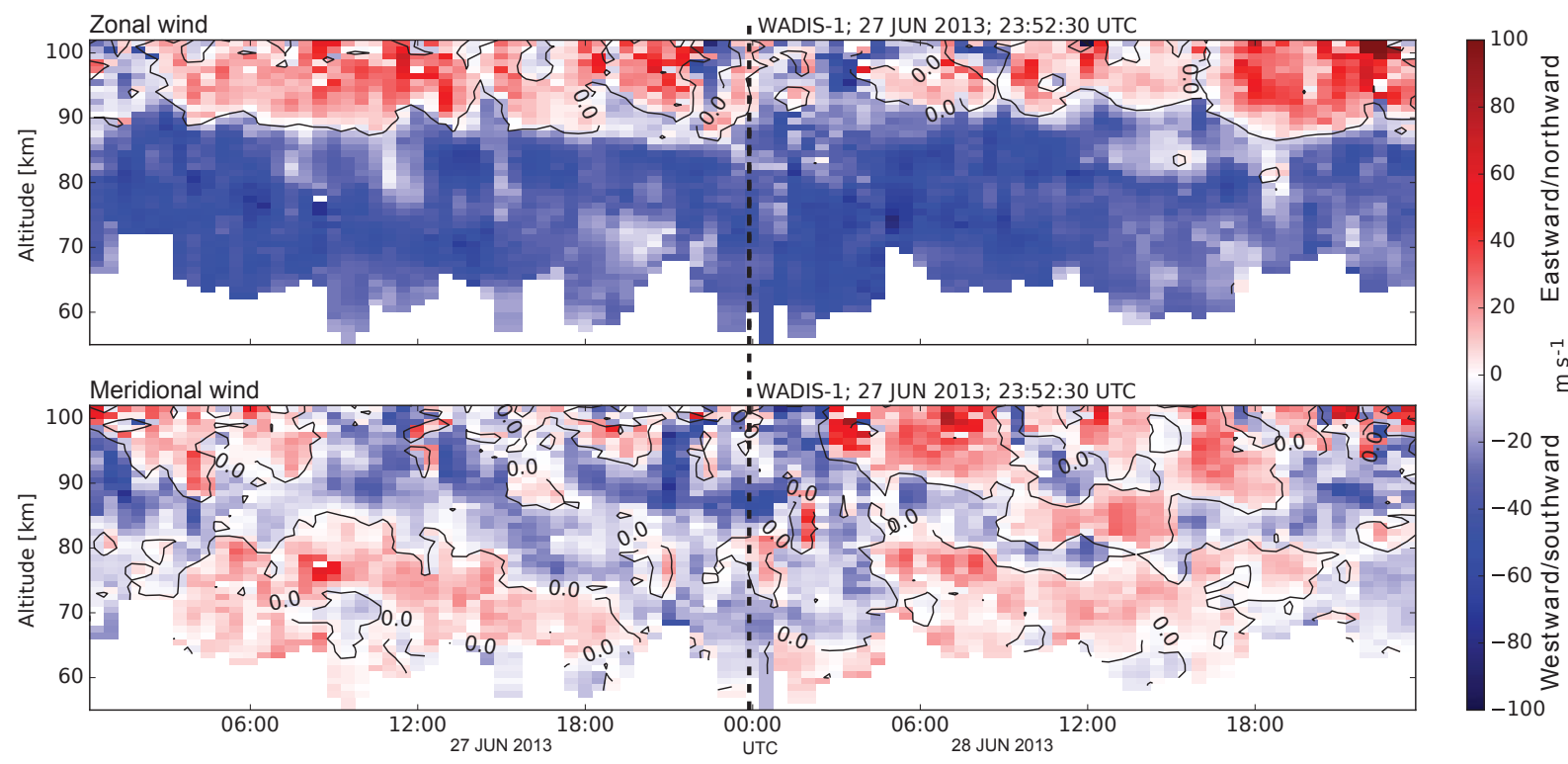

Figure 8. Wind measurements by SAURA-MF radar around WADIS-1 sounding rocket launch. Black isolines mark zero wind.

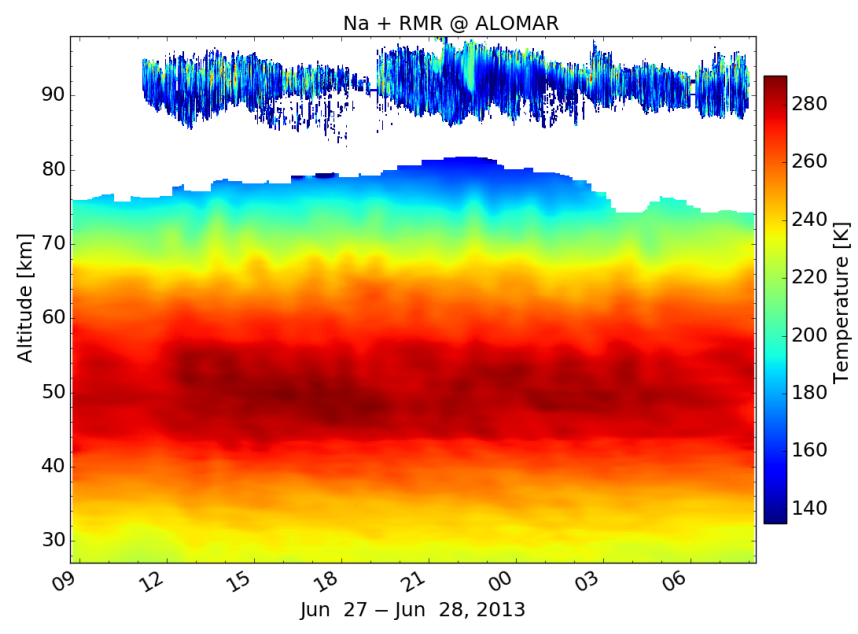

Figure 9. Temperature field measured with RMR (lower part) and $\mathrm{Na}$ lidar (upper part) around WADIS-1 sounding rocket launch (27 June 2013, 23:52:30 UTC).

ments are only available on a campaign basis, which makes it difficult to get a large data set of concurrent measurements with MAARSY. However, the $5 \mathrm{~h}$ of the EISCAT measurements yield important geophysical information, discussed in Sect. 6.

The MAARSY beam geometry at those heights was set up for $\sim 10 \mathrm{~km}$ horizontal extent, and the maximum $\varepsilon$ gradient value observed during WADIS-1 campaign was only $3 \mathrm{~mW} \mathrm{~kg} \mathrm{~km}^{-1}$. On the other hand, MAARSY yields continuous observations and therefore allows investigations of temporal evolution of mesospheric turbulence, which are discussed below.

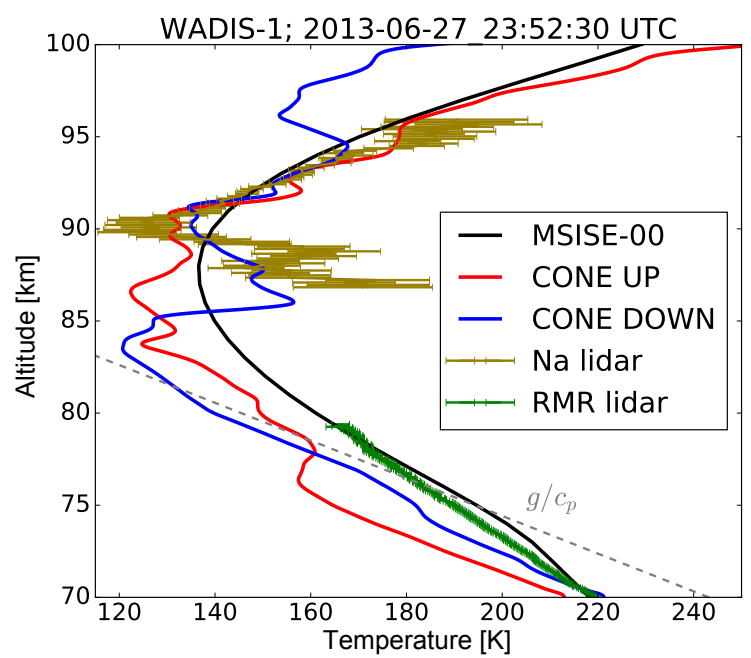

Figure 10. Simultaneously measured temperature profiles during WADIS-1 launch. The rocket-borne measurements were done with the ionization gauge CONE. See text for details.

To summarize, even though the MAARSY turbulence measurements are somewhat limited in magnitude of $\varepsilon$ values, their vertical mean agrees reasonably with the mean over the same height range derived by the reliable in situ technique.

\section{Analysis}

As shown in the previous section, comparison of instant rocket measurements with the radar PMSE observations suggests that the mean values of turbulence energy dissipation 


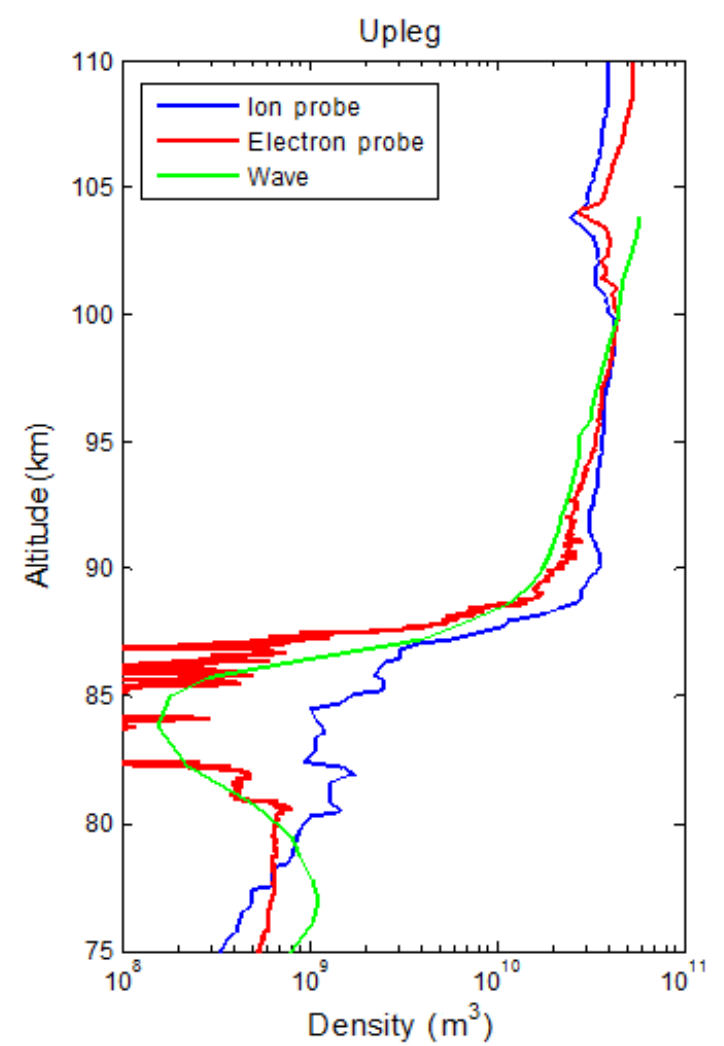

Figure 11. Plasma density measurements during upleg of the WADIS-1 rocket flight. The green line shows absolute electron densities measured with the radio-wave propagation experiment. The blue and red lines are for ion and electron densities, respectively.

rates obtained from the entire hight range between 80 and $90 \mathrm{~km}$ by radar and in situ techniques agree reasonably well. This implies that by considering the vertical mean (i.e., average value over measurement range) a more appropriate picture of the mesospheric turbulence field can be inferred from the radar observations.

In this section we first validate this statement by analyzing distributions of the turbulence energy dissipation rates in terms of mean values and compare them with distributions of instant $\varepsilon$ values. Next, we study variation in the mean $\varepsilon$ value on different temporal and spatial scales.

\subsection{Turbulence variability}

Figure 13 shows histograms of all measured single $\varepsilon$ values for $5 \mathrm{~h}$ of the EISCAT and MAARSY measurements during the WADIS-1 launch night (red and green, respectively), as well as in situ measurements (blue).

First of all, due to their high sensitivity, the rocket-borne $\varepsilon$ measurements reveal a much broader distribution than those derived from the radar measurements. In situ measured turbulence energy dissipation rates span over five decades, whereas radar measurements only vary by 3.5 and 4 orders of magnitude for MAARSY and EISCAT, respectively.
Also, the in situ data reveal two subsets separated at $\varepsilon=$ $10 \mathrm{~mW} \mathrm{~kg}^{-1}$. The subset with high energy dissipation rates results from the strong turbulent sub-layers observed on the downleg.

The solid lines in Fig. 13 show the probability density functions (PDFs) for normal distributions of $\log _{10}(\varepsilon)$, fitted to the respective histograms. Interestingly, the widths of these PDFs for both radar data sets are equal to the third decimal digit, $\sigma=0.489$ in $\log _{10}$ space. The subset of in situ data with higher $\varepsilon$ values (i.e., $10^{1}-10^{4} \mathrm{~mW} \mathrm{~kg}^{-1}$ ) has broader width of $\sigma=0.750$ in $\log$ space. The mean values in $\log _{10}$ space for these distributions of single $\varepsilon$ points in the range $80-90 \mathrm{~km}$ are highest for the EISCAT and smallest for the in situ measurements. The dynamic range of the $\varepsilon$ values, i.e., $[\max (\varepsilon)-\min (\varepsilon)]$, is also larger for EISCAT than for MAARSY data. The in situ data reveal a larger range of the observed turbulence energy dissipation rates, and if we fit a single PDF to the entire range of the measured dissipation rates, i.e. from $10^{-1}$ to $10^{4} \mathrm{~mW} \mathrm{~kg}^{-1}$, it reveals $\sigma\left(\log _{10}(\varepsilon)\right) \approx 1$ (discussed below and shown in Fig. 15).

Next, we look how vertical mean values derived from the radar measurements are distributed by their magnitude. The same sort of distributions as in Fig. 13, but for vertical mean of the radar measurements between 80 and $90 \mathrm{~km}$ are shown in Fig. 14. The PDFs of the vertical means are closer to the in situ data and the $\sigma$ values are equal to the first decimal digit, $\sigma=0.5$. Also, the entire distribution lies closer to the in situ data.

Now, we take larger data sets, which are available for us for the in situ and MAARSY measurements and compare the same statistics in Fig. 15. The statistics of all the rocket-borne turbulence measurements in summer (Szewczyk, 2015) in the altitude range between 80 and $90 \mathrm{~km}$ are shown in Fig. 15 in black. It yields a mean of $\varepsilon \approx 10 \mathrm{~mW} \mathrm{~kg}^{-1}$ and $\sigma \approx 1$ in $\log _{10}$ space (Szewczyk, 2015). The highest $\varepsilon$ values in the total statistics only slightly exceed those derived from the WADIS-1 flight data. However, the entire $\varepsilon$ range is broader by 2 orders of magnitude and thereby spans over seven decades of $\varepsilon$ values. The blue line in Fig. 15 shows PDFs fitted to the entire (not split) set of the WADIS-1 rocket-borne measurements.

The histogram of all MAARSY turbulence measurements during the PMSE season of the year 2013 is shown in Fig. 15 in green. The histogram represents distribution of the vertical mean $\varepsilon$ values obtained by MAARSY between 80 and $90 \mathrm{~km}$ height. The solid line shows the corresponding PDF and the dashed line shows PDFs derived for distribution of single $\varepsilon$ values similar to those, shown in Fig. 13, but for the entire PMSE season 2013 (the corresponding histogram is not shown here). It is apparent that the rocket-borne and the MAARSY mean-based $\varepsilon$ distributions reveal close mean values (i.e., peak of the probability) of about $10 \mathrm{~mW} \mathrm{~kg}^{-1}$. The width of the distributions, $\sigma$, is 1.5 orders of magnitude larger for the in situ measurements than for mean MAARSY observations. It is seen from the MAARSY measurements statis- 


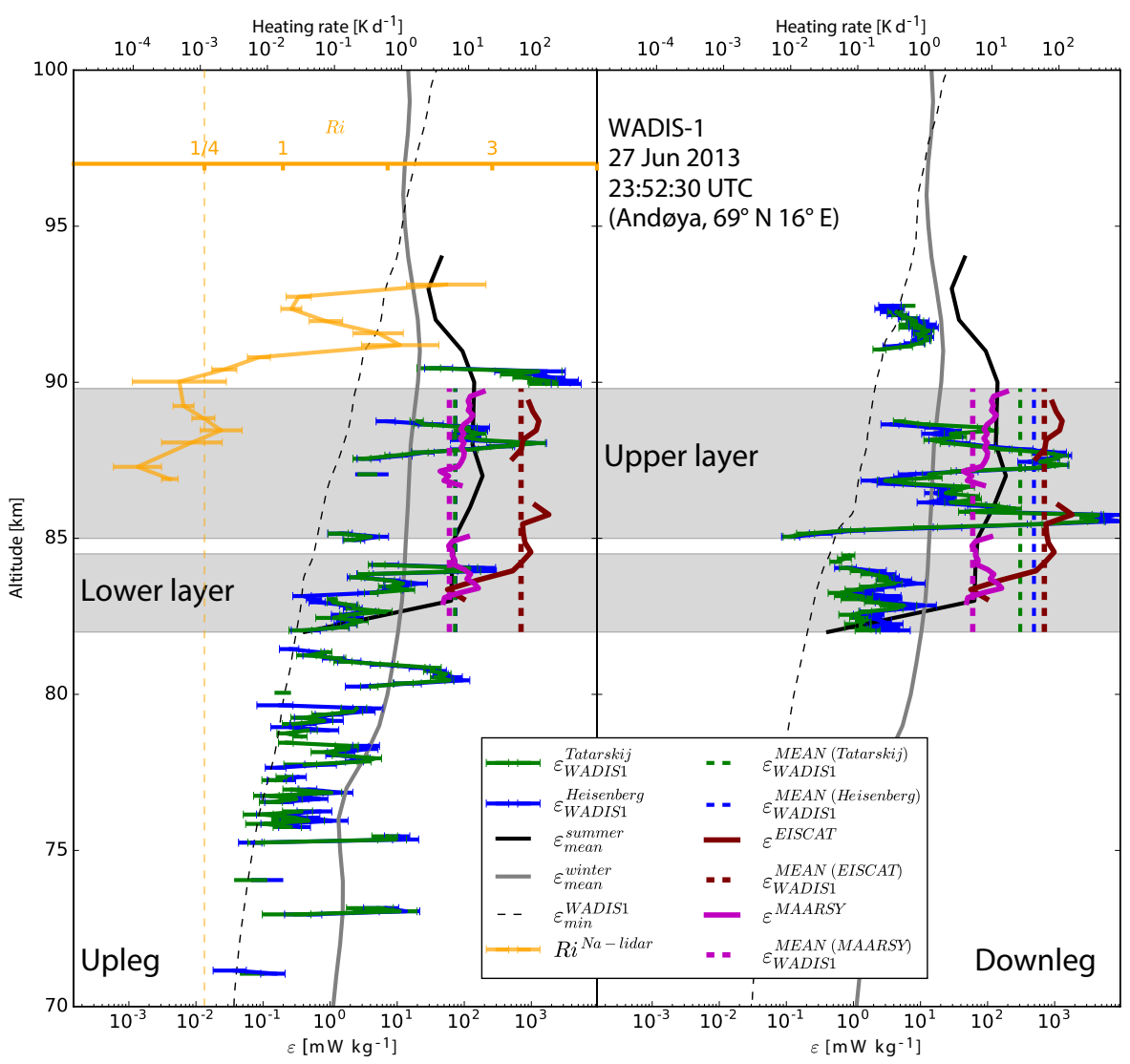

Figure 12. Turbulence energy dissipation rates measurements during the WADIS-1 sounding rocket flight. The left and right panel show upand downleg data, respectively. Blue and green lines show the $\varepsilon$ values derived from the CONE measurements using Heisenberg (1948) and Tatarskii (1971) spectral models. Magenta and dark red are for the vertical beam measurements with MAARSY and EISCAT VHF radar. The solid gray and black lines show $\varepsilon$ climatologies for winter (Lübken, 1997) and summer (Lübken et al., 2002). The vertical colored dashed lines show vertical means between 80 and $90 \mathrm{~km},\langle\varepsilon\rangle$. The colors are the same as for instant values. Black dashed line shows $\varepsilon_{\text {min }}=v \times \omega_{B}^{2}$.

tics that distribution of the vertical mean $\varepsilon$ values is centered at values almost 1 order of magnitude smaller and thereby agrees better with the in situ statistics, than that of the single $\varepsilon$ points (Fig. 15, dashed line).

To summarize, the comparison of statistical distributions of $\varepsilon$ values derived using different approaches in the altitude range $80-90 \mathrm{~km}$ shows that probability to measure mean value of the energy dissipation rate by MAARSY is close to those by the in situ results. Further, in Sect. 6.3 we will show that this vertical mean $\varepsilon$ value reflects wave activity at different timescales, which is otherwise not seen.

\subsection{Wave modulation of $\varepsilon$ profiles in space}

Another interesting feature apparent in the in situ measurements is the wavelike behavior of the $\varepsilon$ profiles. It is especially seen in the downleg data (Fig. 12, right panel). It is intuitive to suggest that this might be a signature of gravity waves that could, for example, modulate the turbulence field.

In situ measurements of the background density and/or temperature can be used to derive vertical wavelengths of the gravity waves in the same measurement volume, getting insight into the observed oscillating feature. Since the turbulence field in the MLT is essentially intermittent, and therefore the in situ measured energy dissipation rate profiles have many singularities, we apply the Lomb-Scargle spectral analysis technique (Scargle, 1982) to infer wavelengths of the observed modulation. The Lomb-Scargle scalograms of the two in situ measured $\varepsilon$ profiles are shown in Fig. 16 as green lines. For consistency, we use the same technique to infer GW parameters from the relative fluctuations of density and temperature which are shown in Fig. 16 as blue and red lines, respectively. The upper panel of Fig. 16 shows upleg data and the lower panel is for downleg measurements.

Both up- and downleg data reveal most pronounced spectral peaks inferred from density and temperature fluctuations at $\sim 3.2 \mathrm{~km}$. The upleg turbulence measurements also reveal a strong signature at this scale, but not the downleg $\varepsilon$ measurements. The upleg data also reveal an obvious and pronounced maximum at $5 \mathrm{~km}$ scale in both density and temperature fluctuations as well as in the spectral morphology of the turbulence energy dissipation rates. The downleg data 

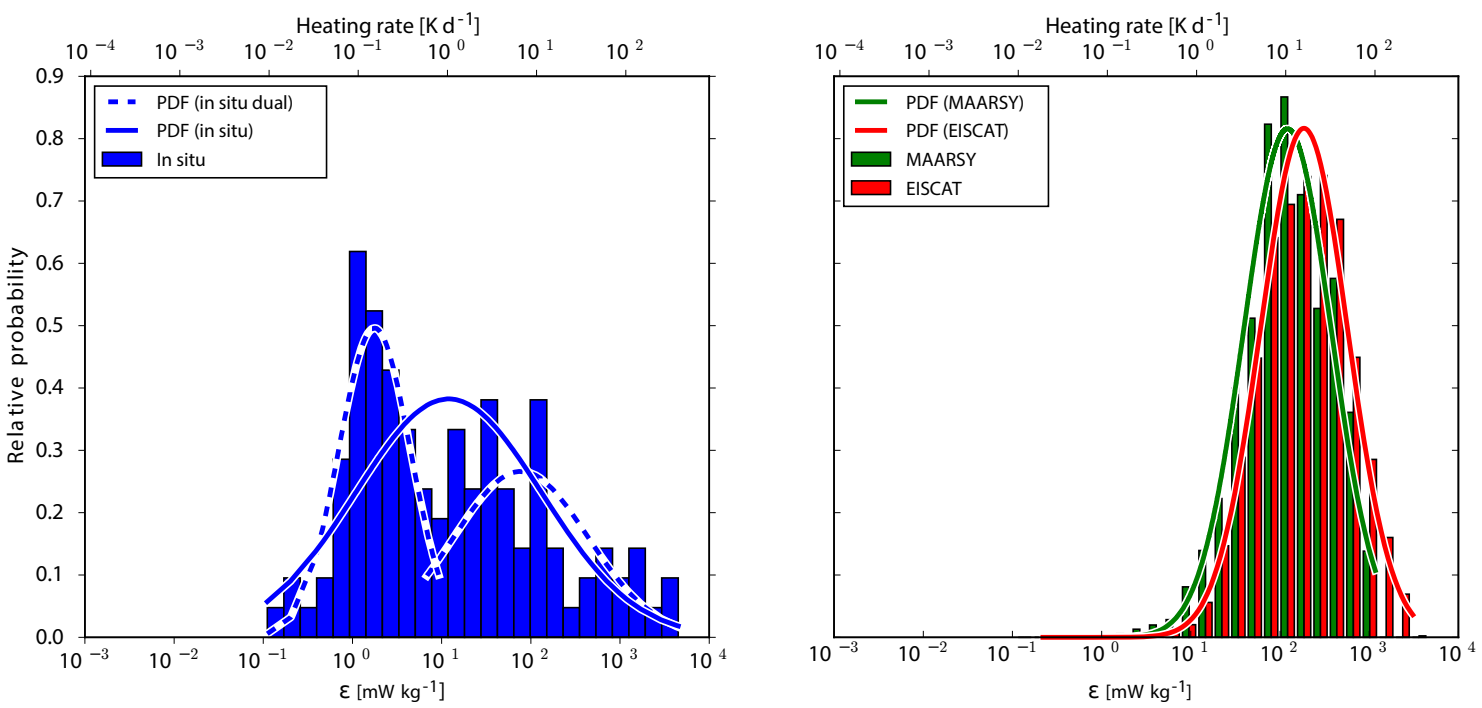

Figure 13. Distributions (histograms) of turbulence energy dissipation rates derived from the EISCAT, MAARSY, and in situ measurements in red, green, and blue, respectively, around the WADIS-1 launch. Solid lines show probability distribution functions (PDF) fitted to the corresponding histograms. Since the histogram of in situ data may suggest two subsets, it was additionally split at $10 \mathrm{~mW} \mathrm{~kg}^{-1}$ for the PDF fitting (dashed lines).

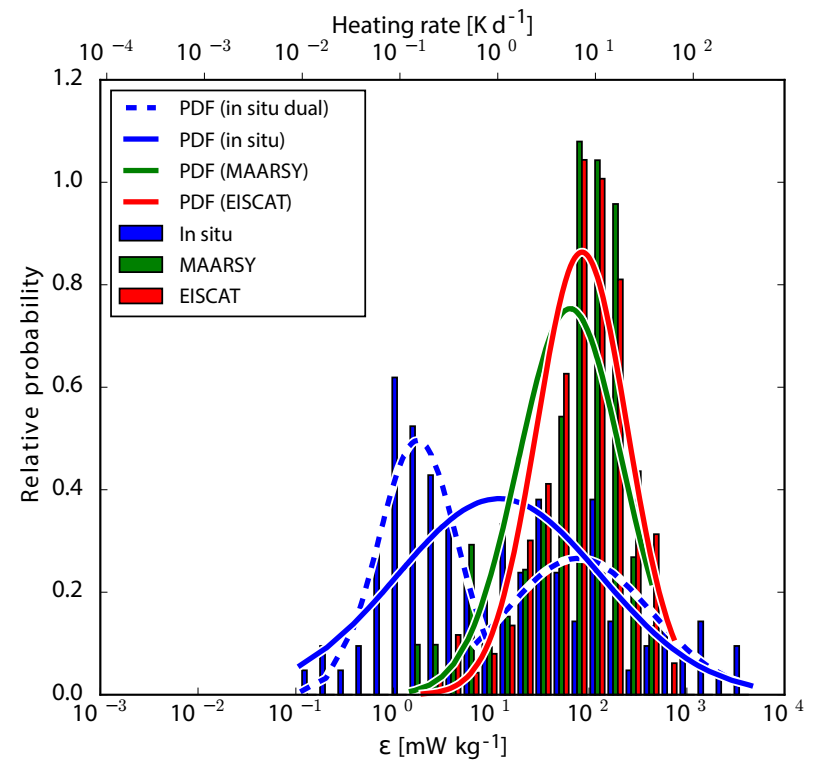

Figure 14. The same as Fig. 13 but for the vertical means between 80 and $90 \mathrm{~km}$ heights for the EISCAT and MAARSY data. See text for details.

reveal a wealth of wavelengths larger than the $5 \mathrm{~km}$ apparent in the upleg measurements, which are merged and cannot be discriminated. The wavelength range from about 2 to $10 \mathrm{~km}$ is characteristic for gravity waves propagating to the MLT region (e.g., Holton, 1982; Fritts et al., 2014) and suggests a modulation of the turbulence dissipation field by gravity waves.

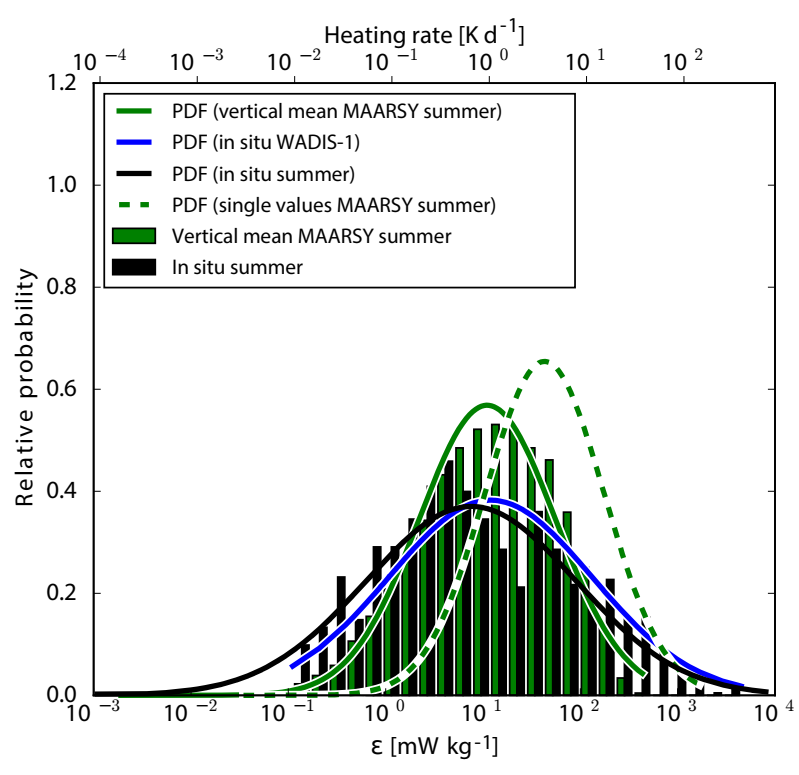

Figure 15. Distributions of the turbulence energy dissipation rates, derived from MAARSY during PMSE season 2013 (green), from all the rocket-borne measurements (black), and from in situ WADIS-1 measurements (blue). All data were measured between 80 and $90 \mathrm{~km}$. The dashed green line shows the distribution of single $\varepsilon$ values, whereas the solid green line and histogram represent vertical mean values.

Both upleg and downleg $\varepsilon$ profiles also reveal clear signatures at smaller scales, i.e. $\sim 2.1, \sim 1.5$, and $\sim 1 \mathrm{~km}$ (see Fig. 16). At the same time, only the downleg measurements of temperature and density fluctuations clearly show the pres- 


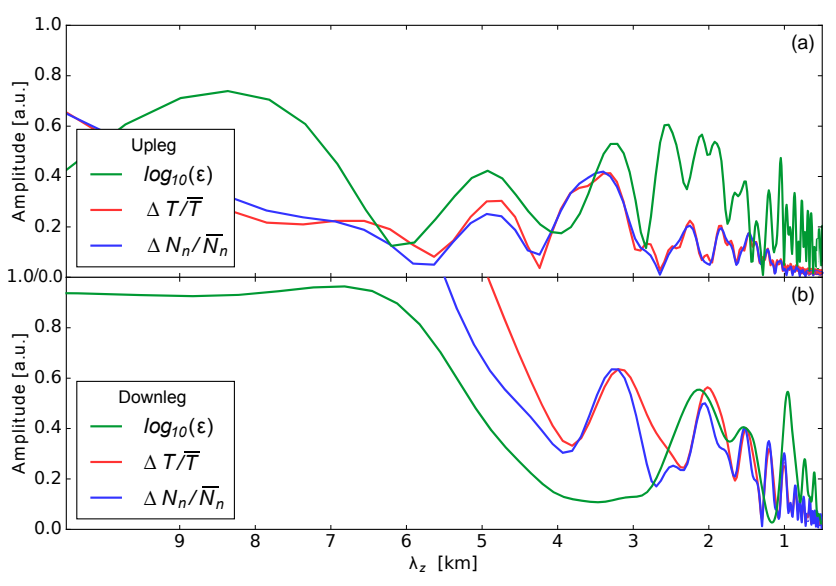

Figure 16. Lomb-Scargle scalogram of the in situ measured $\varepsilon$ profiles shown in Fig. 12 as green and of the temperature (red) and density (blue) fluctuations derived from the in situ measured data (Fig. 10). The upper and lower panel show up- and downleg data, respectively.

ence of peaks at the $\sim 2.1$ and $\sim 1.5 \mathrm{~km}$ wavelengths. The smallest scale of the strong wavelike modulation of both $\varepsilon$ profiles at $\sim 1 \mathrm{~km}$ is not so clearly present in the in situ temperature and density profiles.

To summarize, the spatial variation in the in situ measured turbulence energy dissipation rates shows wavelike modulations typical for the MLT-GW range of wavelengths and thereby suggests that the morphologies of these two dynamical processes are ultimately coupled. If the observed oscillating behavior of the $\varepsilon$ profiles is indeed a signature of gravity waves, we should be able to find similar signatures in other turbulence measurements, e.g., in MAARSY data.

\subsection{Wave modulation of $\langle\varepsilon\rangle$ profiles in time}

In Sect. 6.1 we showed that the vertical mean over the altitude range $80-90 \mathrm{~km}$ of radar $\varepsilon$ measurements appears to be a suitable measure of the overall turbulence activity for a given time. In this section we investigate how this mean varies in time. Figure 17 shows variation in the vertical mean of the MAARSY turbulence measurements, with full time resolution shown by the blue line. Similarly, the green line represents the full time resolution of the mean of the EISCAT turbulence measurements. Bold red and black lines were derived as running means of the blue and green profiles for MAARSY and EISCAT, respectively.

Figure 17 shows quite prominent wavelike features with smaller modulations at about $1 \mathrm{~h}$ periods modulated by an about $24 \mathrm{~h}$ wave. The short-period $(\sim \mathrm{h}) \varepsilon$ variations have amplitudes of up to $\sim 1$ order of magnitude, whereas $24 \mathrm{~h}$ modulation introduces change of up to $\sim 2$ orders of magnitude in the energy dissipation value.

The general trend of the $5 \mathrm{~h}$ of EISCAT measurements during the WADIS-1 launch night falls quite well on the
MAARSY data, suggesting that both radars might reveal similar time variability.

Since the MAARSY-based measured vertical mean of turbulence energy dissipation rate is available for the entire season, we constructed a continuous and smooth time series that can be analyzed applying, for example, the Fourier analysis technique. The resulting power spectrum is shown in Fig. 18. The $24 \mathrm{~h}$ period inferred from the time-series plot (Fig. 17) is clearly seen as a peak in the spectrum, and its significance can be judged by the naked eye. Also, a $12 \mathrm{~h}$ peak is apparent in the spectrum in Fig. 18.

By applying different filters and looking at the spectrum of the shown in Fig. 17 time series, but over the entire season, one can also find some short-period wave signatures, which are not pronounced in the spectrum of the full-resolution data shown in Fig. 18. Thus, one can isolate, for example, 1.6 and $0.9 \mathrm{~h}$ peaks in the spectrum which are also apparent in the time-series plot (Fig. 17).

\section{Discussion}

As described above, radar wind measurements show a relatively stable wind field in the height range $80-90 \mathrm{~km}$. That is, there were no wind shears that could produce turbulent structures. This suggests that the observed turbulence activity can likely be attributed to GW breakdown processes. At the same time, temperature measurements show strong GW activity at those heights and reduced wave amplitudes right above the $90 \mathrm{~km}$ altitude. The two temperature profiles measured in situ were horizontally separated by $\sim 30 \mathrm{~km}$ at an altitude of $\sim 80 \mathrm{~km}$ and show a temperature difference of $\sim 35 \mathrm{~K}$. This difference could possibly result from, for example, a GW with a horizontal wavelength of $\sim 60 \mathrm{~km}$ and amplitude of $17.5 \mathrm{~K}$. On the other hand, this difference might be a demonstration of horizontal variability in the GW amplitudes in MLT. That is, the temperature difference could be produced by independent $\mathrm{GW}$ packages.

Temperature profile measured in situ on the downleg shows huge fluctuations around $85 \mathrm{~km}$. The same data reveal turbulence layers with very high energy dissipation values at those heights. Interestingly, such a strong temperature enhancement of $40 \mathrm{~K}$ accompanied by vigorous turbulence that was measured by the WADIS- 1 rocket was also observed by Szewczyk et al. (2013) and led to a mesospheric temperature inversion layer (MIL). In their case a MIL was seen for a long time in lidar data and also revealed a mesoscale extent as was inferred from satellite temperature measurements. In our case we deal with an event that is shorter on both temporal and spatial scales.

Somewhat smaller GW amplitudes seen in the upleg in situ temperature data are accompanied by weaker turbulence. The MAARSY turbulence measurements located spatially close to the rocket's ascent also show similar $\langle\varepsilon\rangle$ values. The EISCAT turbulence measurements were done at $\sim 100 \mathrm{~km}$ 


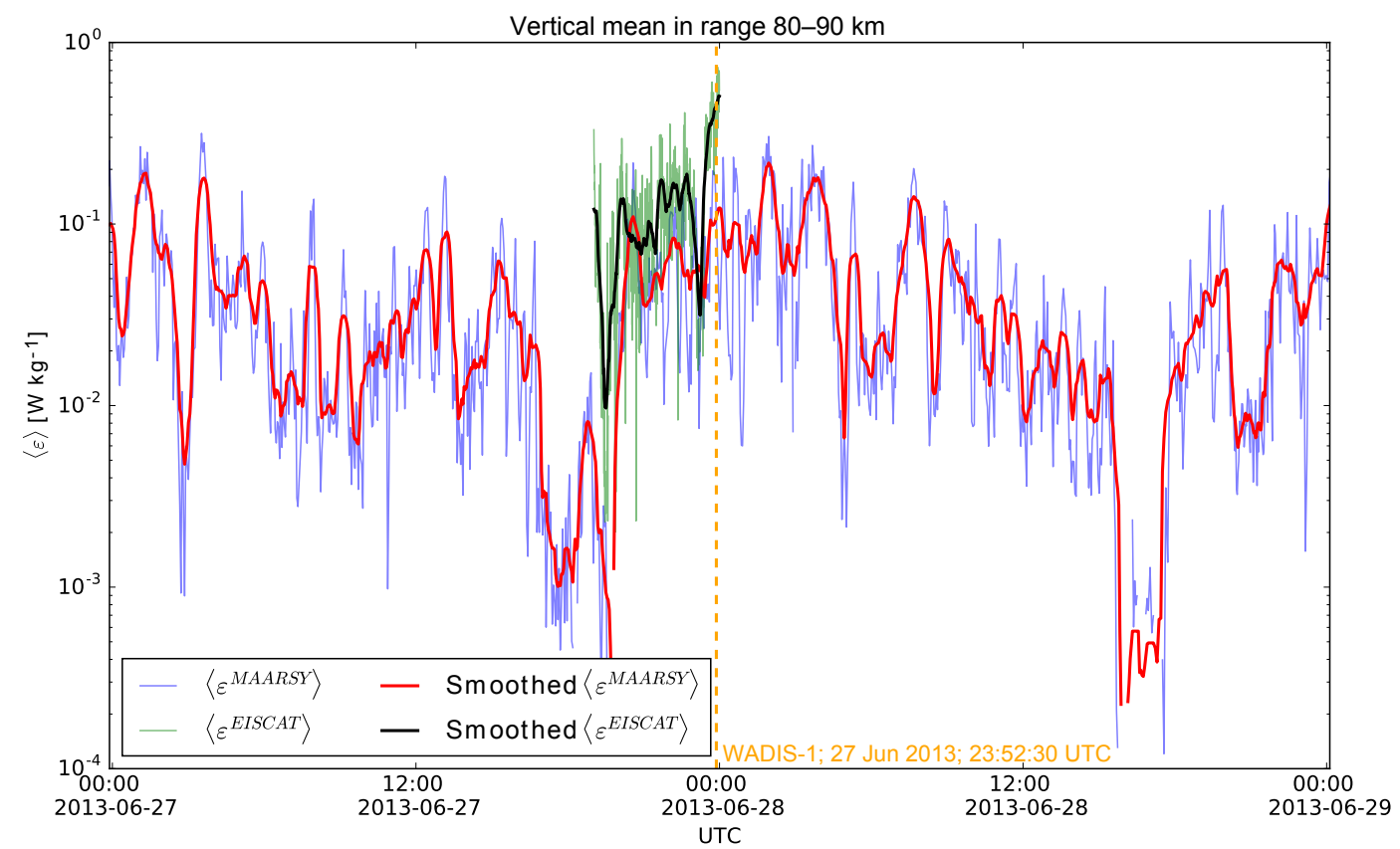

Figure 17. Vertical mean over altitude range $80-90 \mathrm{~km}$ of radar turbulence measurements. Blue and green are MAARSY and EISCAT measurements with full time resolution. Bold red and black lines were derived as running means of the blue and green profiles for MAARSY and EISCAT, respectively.

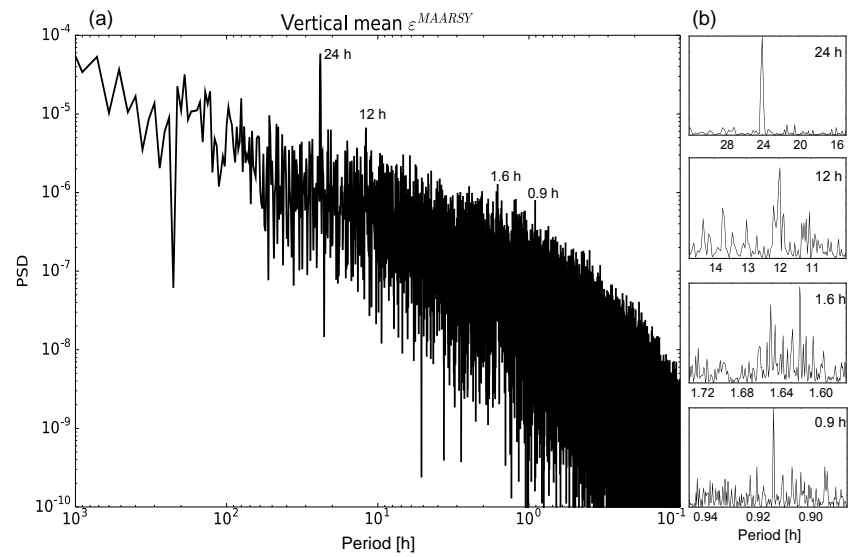

Figure 18. Left: power spectral density derived by applying fast Fourier transform to a time series of vertical means between 80 and $90 \mathrm{~km}$ of MAARSY turbulence measurements during PMSE season 2013, i.e. 1 May to 31 August. Right column: zoom in on selected periods marked on the left panel. Note linear scales for both axes.

horizontal distance and show strong turbulence similar to those measured on the rocket's descent. Note that the rocket's upleg is spatially located between the downleg and the EISCAT sites. Since we consider simultaneous measurements, these differences are consistent with an assumption that the turbulence field is modulated by atmospheric waves with horizontal wavelength of the order of $60 \mathrm{~km}$, and we observed $\langle\varepsilon\rangle$ variation that corresponds to the experiment geometry

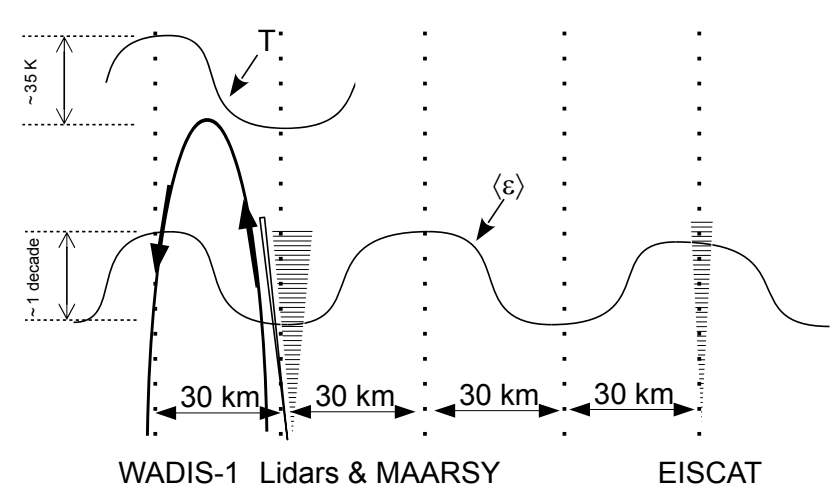

Figure 19. Schematics of the observed spatial variability: $\langle\varepsilon\rangle$ modulation, temperature variation, and its relation to the locations of measurements. See text for details.

sketched in Fig. 19. The temperature variations shown in Fig. 10 also suggested the presence of GWs with horizontal wavelength $\lambda_{\text {hor }} \approx 60 \mathrm{~km}$. This horizontal variation in temperature appears to be in phase with the $\langle\varepsilon\rangle$ modulation in the spatial domain, as sketched in Fig. 19.

The difference in the vertical mean energy dissipation rates, $\langle\varepsilon\rangle$, is on average almost an order of magnitude at horizontal scales of $\sim 30$ and $\sim 100 \mathrm{~km}$. This is a clear manifestation of the spatial variability in the MLT dissipation field and is consistent with the hypothesis of $\langle\varepsilon\rangle$ modulation by a $\mathrm{GW}$ in the spatial domain. 


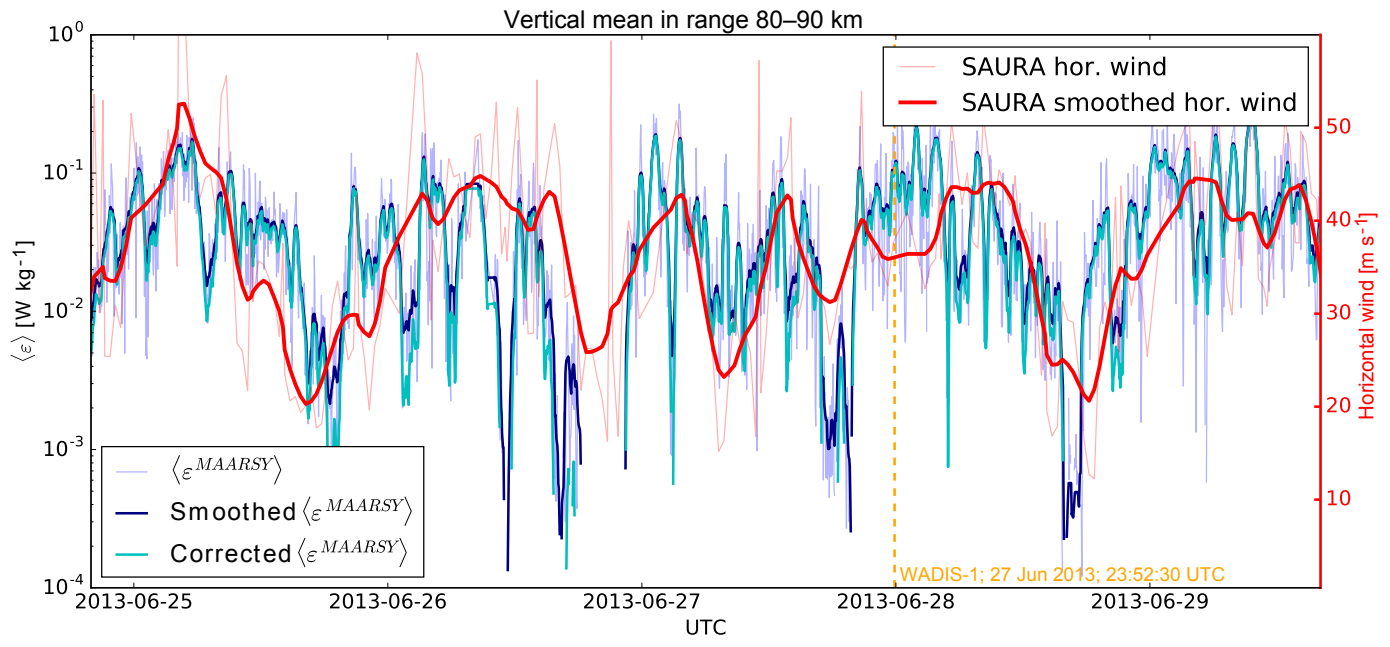

Figure 20. Vertical mean values over altitude range 80-90 km. Thin semitransparent lines show full-resolution data, while bold lines show running mean values. Dark- and light-blue bold profiles show $\langle\varepsilon\rangle$ values for MAARSY before and after applying correction for horizontal wind, respectively. Red lines and the right $y$ axis show SAURA measurements of horizontal wind.

The in situ measured turbulence energy dissipation rates profiles also reveal a wavelike modulation in magnitude. Our analysis shows that both GWs and $\varepsilon$ profiles reveal vertical wavelengths of 2 to $10 \mathrm{~km}$, which can be attributed to GWs. On the other hand, both $\varepsilon$ profiles show a pronounced signature at $1 \mathrm{~km}$ scale which is not present in density or temperature fluctuation data. The $1 \mathrm{~km}$ structure might be an internal feature of the MLT turbulence field. We have no reasonable explanation for this so far and will look for such a behavior in other turbulence data.

The summer turbulence climatology by Lübken et al. (2002) shows that the main region of turbulence generation observed at high northern latitudes is located between 82 and $\sim 95 \mathrm{~km}$ height. This can be explained by seasonal conditions for the GW propagation, in particular by critical layer filtering of GWs in the troposphere and stratosphere (e.g., Lindzen, 1981; Holton, 1982; Fritts and Alexander, 2003).

The small-scale GWs characterized by vertical wavelengths in the MLT of less than $\sim 10 \mathrm{~km}$ are one of the large uncertainties for, for example, climate models since they occur at so-called sub-grid scales which cannot be resolved internally in such models. Their action is parametrized by, for example, mean amount of dissipation that they produce in the MLT. The WADIS-1 rocket campaign shows that these wavelengths are also apparent in the MLT dissipation field when considering spatial $\varepsilon$ variability. Exact mechanism for such vertical modulation is a subject for our future work. At this point we can only speculate, for example, that occasionally a certain spectrum of GWs made such favorable conditions that we were able to observe the pronounced modulation, which simply reflected the breakdown process of isolated GWs, thereby creating turbulent layers separated by a GW wavelength.
Vast efforts have been made to derive turbulence energy dissipation field in the MLT by means of radar soundings (e.g., Hocking, 1983, 1985; Hall et al., 1998, 2003; Strelnikova and Rapp, 2013; Lübken, 2014). It is understood that the radar-based turbulence measurements can be biased by both instrumental effects as well as some GWs' contributions to the measured variances of the wind fluctuations. Intercomparison of the radar-based and in situ measured turbulence energy dissipation rates has always been difficult to interpret (e.g., Engler et al., 2005). Our statistical distributions shown in Fig. 13 and dashed line in Fig. 15 reveal large discrepancies between the $\varepsilon$ values derived by the different techniques. It was argued that radars probe much larger volumes which, in turn, might only partly be filled with turbulence. Hocking (1985) summarized radar turbulence measurements available to that date and found that the median values measured between 80 and $90 \mathrm{~km}$ fall within the range 0.05 to $0.1 \mathrm{~mW} \mathrm{~kg}^{-1}$. This range agrees reasonably well with our statistics when considering single $\varepsilon$ points, i.e., with Fig. 13 and dashed line in Fig. 15.

As mentioned above, summer conditions suggest that turbulence appears mainly in the range $82-95 \mathrm{~km}$. Also, as shown by Rapp and Lübken (2004) PMSEs can be considered (to a first approximation) an acceptable proxy for turbulence occurrence. That is, if a PMSE is present, then either active or fossil turbulence must also be present there. This suggests that the non-turbulent part of the probed volume can be considered as revealing a dissipation value of zero. This way the derived mean dissipation value agrees with in situ measurements as shown in Figs. 14 and 15 and in time domain reveals an oscillatory behavior.

Next, we discuss possible biases in these oscillations. The instrumental effect, the so-called beam broadening (Hocking, 1983), could potentially cause an increase in the measured 
spectral width. This undesirable effect can be significant for broad beam radars. It results in the broadening of the Doppler spectrum by projection of the horizontal wind on the tilted part of the beam. This effect can be corrected if we know the horizontal wind speed (e.g., Hocking, 1985). The MAARSY and the EISCAT radars used in this study have very narrow beam and range gate. This implies that the correction term is rather small and only small $\varepsilon$ values will be affected by this correction. That is, this correction will not change the general oscillating behavior of the observed mean energy dissipation rates. Analysis of wind measurements by either MAARSY or SAURA radars during the PMSE season 2013 shows that horizontal wind speed in the height range $80-90 \mathrm{~km}$ reaches average values of $\sim 60 \mathrm{~m} \mathrm{~s}^{-1}$. For the MAARSY beam width of $3.6^{\circ}$, this can result in a beam broadening that will produce at most $1.2 \mathrm{~m} \mathrm{~s}^{-1}$ bias in spectral width estimates. This in turn leads to bias in the derived energy dissipation rates of $\varepsilon_{\mathrm{err}} \approx 7.8 \mathrm{~mW} \mathrm{~kg}^{-1}$. High values of turbulence energy dissipation rates derived from the radar observations are of the order of $10^{3} \mathrm{~mW} \mathrm{~kg}^{-1}$ and the bias of $\sim 8 \mathrm{~mW} \mathrm{~kg}^{-1}$ can be considered negligible. It is also well known that such a correction can be larger than the measured spectral width (e.g., Hocking et al., 2016, and references therein). In our analysis about $8 \%$ of the data points during the PMSE season 2013 turned negative after applying this wind correction. However, the maximum value affected by such an overcorrection was $\langle\varepsilon\rangle=10.6 \mathrm{~mW} \mathrm{~kg}^{-1}$, which is in accord with the above estimate. Figure 20 demonstrates the applied correction for nonturbulent beam broadening. Dark-blue thin and bold lines in Fig. 20 show the same $\langle\varepsilon\rangle$ data as blue and red profiles in Fig. 17, respectively. The light-blue line in Fig. 20 shows the corrected $\langle\varepsilon\rangle$ values.

In Fig. 20 we additionally compare the mean turbulence energy dissipation rates, $\langle\varepsilon\rangle$, with horizontal wind observations $\left(\sqrt{u^{2}+v^{2}}\right.$, where $u$ and $v$ are zonal and meridional winds) with the SAURA-MF radar (shown in red). This comparison shows an obvious positive correlation between horizontal wind amplitudes and strength of turbulence on temporal scales of $24 \mathrm{~h}$. As mentioned in Sect. 3 SAURA-MF radar is well suited for observations of tidal waves (e.g., Hoffmann et al., 2010). The spectrum of horizontal wind measurements with SAURA also shows pronounced peaks at 12 and $24 \mathrm{~h}$ periods (not shown here).

The simplest explanation can be that the background horizontal wind modulates the favorable conditions for wave breaking. This results in more breaking events when horizontal wind increases. However, one should also consider the sources and propagation conditions to make a more solid statement. A deeper investigation of such wave modulations of the turbulence field and its connection to the properties of atmospheric waves is a subject of our future work and is beyond the scope of this paper.

\section{Conclusions}

In this paper we presented results of turbulence measurements during the WADIS- 1 sounding rocket campaign. A unique feature of the WADIS project is multi-point turbulence sounding by applying different measurement techniques. This allowed us to observe horizontal variability in the turbulence field in the MLT. We found that turbulence dissipation rate values vary in space in a wavelike manner both in horizontal and vertical direction. This wavelike modulation reveals the same vertical wavelengths as those seen in the gravity waves.

We also found that the vertical mean value of the radar-based turbulence measurements agrees reasonably with rocket-borne measurements, which is to date the most precise turbulence measurement technique in the MLT region. In this way defined $\left\langle\varepsilon_{\text {radar }}\right\rangle$ value reveals clear tidal modulation and results in up to two decades of variation with periods of $24 \mathrm{~h}$. This modulation appeared to be in phase with tidal change of horizontal wind observed by SAURA-MF radar. Mean turbulence energy dissipation rates also show $12 \mathrm{~h}$ and shorter ( $\sim$ hours) modulations resulting in one decade variation. Such tidal modulation of the turbulence dissipation field in the MLT region inferred from this analysis is to our knowledge a new finding that has so far not been explicitly stated in the literature.

Data availability. The EISCAT data are freely available at https: //www.eiscat.se/. To access other data, please contact the authors.

Competing interests. The authors declare that they have no conflict of interest.

Acknowledgements. This work was supported by the German Space Agency (DLR) under grant 50 OE 1001 (project WADIS). The authors thank DLR-MORABA for their excellent contribution to the project by developing the complicated WADIS payload and campaign support together with the Andøya Space Center, as well as H.-J. Heckl and T. Köpnick for building the rocket instrumentation. EISCAT is an international association supported by the research councils of Norway, Sweden, Finland, Japan, China, and the United Kingdom.

The topical editor, C. Jacobi, thanks two anonymous referees for help in evaluating this paper.

\section{References}

Achatz, U.: On the role of optimal perturbations in the instability of monochromatic gravity waves, Phys. Fluids, 17, 094107094107, doi:10.1063/1.2046709, 2005.

Becker, E. and Schmitz, G.: Climatological Effects of Orography and Land-Sea Heating Contrasts on the Gravity Wave-Driven 
Circulation of the Mesosphere, J. Atmos. Sci., 60, 103-118, doi:10.1175/1520-0469(2003)060<0103:CEOOAL > 2.0.CO;2, 2003.

Bennett, F. D. G., Hall, J. E., and Dickinson, P. H. G.: D-region electron densities and collision frequencies from Faraday rotation and differential absorption measurements., J. Atmos. Terr. Phys., 34, 1321-1335, doi:10.1016/0021-9169(72)90188-2, 1972.

Blix, T. A. and Thrane, E.: Middle atmosphere turbulence at high and middle latitudes, ESA SP-317, Cannes-Mandelieu, France, 317, 437-445, 1991.

Blix, T. A., Thrane, E. V., and Andreassen, Ø.: In situ measurements of the fine-scale structure and turbulence in the mesosphere and lower thermosphere by means of electrostatic positive ion probes, J. Geophys. Res., 95, 5533-5548, doi:10.1029/JD095iD05p05533, 1990a.

Blix, T. X., Thrane, E. V., Fritts, D. C., von Zahn, U., Lübken, F.J., Hillert, W., Blood, S. P., Mitchell, J. D., Kokin, G. A., and Pakhomov, S. V.: Small scale structure observed in situ during MAC/EPSILON, J. Atmos. Terr. Phys., 52, 835-854, 1990b.

Driscoll, R. J. and Kennedy, L. A.: A model for the spectrum of passive scalars in an isotropic turbulence field, Phys. Fluids, 28, 72-80, 1985.

Eberhart, M., Löhle, S., Steinbeck, A., Binder, T., and Fasoulas, S.: Measurement of atomic oxygen in the middle atmosphere using solid electrolyte sensors and catalytic probes, Atmos. Meas. Tech., 8, 3701-3714, doi:10.5194/amt-8-3701-2015, 2015.

Eckermann, S. D., Broutman, D., and Knight, H.: Effects of Horizontal Geometrical Spreading on the Parameterization of Orographic Gravity Wave Drag, Part II: Analytical Solutions, J. Atmos. Sci., 72, 2348-2365, doi:10.1175/JAS-D-14-0148.1, 2015a.

Eckermann, S. D., Ma, J., and Broutman, D.: Effects of Horizontal Geometrical Spreading on the Parameterization of Orographic Gravity Wave Drag, Part I: Numerical Transform Solutions, J. Atmos. Sci., 72, 2330-2347, doi:10.1175/JAS-D-140147.1, 2015b.

Engler, N., Latteck, R., Strelnikov, B., Singer, W., and Rapp, M.: Turbulent energy dissipation rates observed by Doppler MST Radar and by rocket-borne instruments during the MIDAS/MaCWAVE campaign 2002, Ann. Geophys., 23, 11471156, 2005.

Formichev, V. I.: The radiative energy budget of the middle atmosphere and its parameterization in general circulation models, J. Atmos. Solar-Terr. Phys., 71, 1577-1585, 2009.

Friedrich, M., Rapp, M., Plane, J. M. C., and Torkar, K. M.: Bite-outs and other depletions of mesospheric electrons, J. Atmos. Solar-Terr. Phys., 73, 2201-2211, doi:10.1016/j.jastp.2010.10.018, 2011.

Fritts, D. C. and Alexander, M. J.: Gravity wave dynamics and effects in the middle atmosphere, Rev. Geophys., 41, 1003, doi:10.1029/2001RG000106, 2003.

Fritts, D. C., Wang, L., Werne, J., Lund, T., and Wan, K.: Gravity Wave Instability Dynamics at High Reynolds Numbers, Part I: Wave Field Evolution at Large Amplitudes and High Frequencies, J. Atmos. Sci., 66, 1126, doi:10.1175/2008JAS2726.1, 2009a.

Fritts, D. C., Wang, L., Werne, J., Lund, T., and Wan, K.: Gravity Wave Instability Dynamics at High Reynolds Numbers. Part II: Turbulence Evolution, Structure, and Anisotropy, J. Atmos. Sci., 66, 1149, doi:10.1175/2008JAS2727.1, 2009b.
Fritts, D. C., Pautet, P.-D., Bossert, K., Taylor, M. J., Williams, B. P. Iimura, H., Yuan, T., Mitchell, N. J., and Stober, G.: Quantifying gravity wave momentum fluxes with Mesosphere Temperature Mappers and correlative instrumentation, J. Geophys. Res.Atmos., 119, 13583-13603, doi:10.1002/2014JD022150, 2014.

Fritts, D. C., Laughman, B., Lund, T. S., and Snively, J. B.: Selfacceleration and instability of gravity wave packets: 1 . Effects of temporal localization, J. Geophys. Res.-Atmos., 120, 87838803, doi:10.1002/2015JD023363, 2015.

Giebeler, J. and Lübken, F.-J.: Density and temperature measurements in the lower thermosphere with the CONE instrument, in: ESA SP-370, 370, p. 101, 1995.

Giebeler, J., Lübken, F.-J., and Nägele, M.: CONE - a new sensor for in-situ observations of neutral and plasma density fluctuations, ESA SP, Montreux, Switzerland, ESA-SP-355, 311-318, 1993.

Goldberg, R. A., Fritts, D. C., Williams, B. P., She, C.-Y., Lübken, F.-J., Rapp, M., Singer, W., Latteck, R., Hoffmann, P., Müllemann, A., Baumgarten, G., Schmidlin, F. J., She, C.-Y., and Krueger, D. A.: The MaCWAVE/MIDAS rocket and groundbased measurements of polar summer dynamics: Overview and mean state structure, Geophys. Res. Lett., 31, L24S02, doi:10.1029/2004GL019411, 2004.

Goldberg, R. A., Fritts, D. C., Schmidlin, F. J., Williams, B. P., Croskey, C. L., Mitchell, J. D., Friedrich, M., Russell III, J. M., Blum, U., and Fricke, K. H.: The MaCWAVE program to study gravity wave influences on the polar mesosphere, Ann. Geophys., 24, 1159-1173, 2006.

Hall, C. M., Meek, C. E., and Manson, A. H.: Turbulent energy dissipation rates from the University of Troms $\varnothing /$ University of Saskatchewan MF radar, J. Atmos. Sol.-Terr. Phy., 60, 437-440, doi:10.1016/S1364-6826(97)00124-7, 1998.

Hall, C. M., Nozawa, S., Meek, C. E., Manson, A. H., and Luo, Y.: Periodicities in energy dissipation rates in the auroral mesosphere/lower thermosphere, Ann. Geophys., 21, 787-796, doi:10.5194/angeo-21-787-2003, 2003.

Hedin, J., Gumbel, J., Stegman, J., and Witt, G.: Use of $\mathrm{O}_{2}$ airglow for calibrating direct atomic oxygen measurements from sounding rockets, Atmos. Meas. Tech., 2, 801-812, doi:10.5194/amt2-801-2009, 2009.

Heisenberg, W.: Zur statistischen Theorie der Turbulenz, Z. Phys., 124, 628-657, doi:10.1007/BF01668899, 1948.

Hillert, W., Lübken, F.-J., and Lehmacher, G.: TOTAL: A rocketborne instrument for high resolution measurements of neutral air turbulence during DYANA, J. Atmos. Terr. Phys., 56, 1835$1852,1994$.

Hocking, W., Röttger, J., Palmer, R., Sato, T., and Chilson, P.: Atmospheric Radar: Application and Science of MST Radars in the Earth's Mesosphere, Stratosphere, Troposphere, and Weakly Ionized Regions, Cambridge University Press, 2016.

Hocking, W. K.: On the extraction of atmospheric turbulence parameters from radar backscatter Doppler spectra - 1. theory, J. Atmos. Terr. Phys., 45, 89-102, 1983.

Hocking, W. K.: Measurement of turbulent energy dissipation rates in the middle atmosphere by radar techniques: A review, Radio Sci., 20, 1403-1422, 1985.

Hoffmann, P., Rapp, M., Fiedler, J., and Latteck, R.: Influence of tides and gravity waves on layering processes in the po- 
lar summer mesopause region, Ann. Geophys., 26, 4013-4022, doi:10.5194/angeo-26-4013-2008, 2008.

Hoffmann, P., Becker, E., Singer, W., and Placke, M.: Seasonal variation of mesospheric waves at northern middle and high latitudes, J. Atmos. Solar-Terr. Phys., 72, 1068-1079, doi:10.1016/j.jastp.2010.07.002, 2010.

Holton, J. R.: The role of gravity wave induced drag and diffusion in the momentum budget of the mesosphere, J. Atmos. Sci., 39, 791-799, doi:10.1175/15200469(1982)039<0791:TROGWI>2.0.CO;2, 1982.

Jacobsen, T. A. and Friedrich, M.: Electron density measurements in the lower D-region, J. Atmos. Terr. Phys., 41, 1195-1200, doi:10.1016/0021-9169(79)90022-9, 1979.

Kaifler, N., Baumgarten, G., Fiedler, J., Latteck, R., Lübken, F.J., and Rapp, M.: Coincident measurements of PMSE and NLC above ALOMAR $\left(69^{\circ} \mathrm{N}, 16^{\circ} \mathrm{E}\right)$ by radar and lidar from 1999 2008, Atmos. Chem. Phys., 11, 1355-1366, doi:10.5194/acp-111355-2011, 2011.

Larsen, M. F.: Winds and shears in the mesosphere and lower thermosphere: Results from four decades of chemical release wind measurements, J. Geophys. Res.-Space, 107, 1215, doi:10.1029/2001JA000218, 2002.

Latteck, R., Singer, W., and Engler, N.: Estimation of spectral width using the dual-beam width method with a narrow beam MF radar, in: ESA SP-350, 530, 339-343, 2003.

Latteck, R., Singer, W., Morris, R. J., Hocking, W. K., Murphy, D. J., Holdsworth, D. A., and Swarnalingam, N.: Similarities and differences in polar mesosphere summer echoes observed in the Arctic and Antarctica, Ann. Geophys., 26, 2795-2806, 2008.

Latteck, R., Singer, W., Rapp, M., Vandepeer, B., Renkwitz, T., Zecha, M., and Stober, G.: MAARSY: The new MST radar on Andøya-System description and first results, Radio Sci., 47, RS1006, doi:10.1029/2011RS004775, 2012.

Lehmacher, G. A., Scott, T. D., Larsen, M. F., Bilén, S. G., Croskey, C. L., Mitchell, J. D., Rapp, M., Lübken, F.-J., and Collins, R. L.: The Turbopause experiment: atmospheric stability and turbulent structure spanning the turbopause altitude, Ann. Geophys., 29, 2327-2339, doi:10.5194/angeo-29-2327-2011, 2011.

Li, Q. and Rapp, M.: PMSE-observations with the EISCAT VHF and UHF-radars: Ice particles and their effect on ambient electron densities, J. Atmos. Solar-Terr. Phys., 104, 270-276, doi:10.1016/j.jastp.2012.10.015, 2013.

Lindzen, R. S.: Turbulence and stress owing to gravity wave and tidal breakdown, J. Geophys. Res., 86, 9707-9714, 1981.

Lübken, F. J.: TOTAL: A new instrument to study turbulent parameters in the mesosphere and lower thermosphere, in: ESA SP-270, 215-218, 1987.

Lübken, F.-J.: On the extraction of turbulent parameters from atmospheric density fluctuations, J. Geophys. Res., 97, 20385-20395, 1992.

Lübken, F.-J.: Seasonal variation of turbulent energy dissipation rates at high latitudes as determined by insitu measurements of neutral density fluctuations, J. Geophys. Res., 102, 1344113456, 1997.

Lübken, F.-J.: Turbulent scattering for radars: A summary, J. Atmos. Sol.-Terr. Phys., 107, 1-7, doi:10.1016/j.jastp.2013.10.015, 2014.

Lübken, F.-J., Hillert, W., Lehmacher, G., and von Zahn, U.: Experiments revealing small impact of turbulence on the energy budget of the mesosphere and lower thermosphere, J. Geophys. Res., 98, 20369-20384, 1993.

Lübken, F.-J., Rapp, M., and Hoffmann, P.: Neutral air turbulence and temperatures in the vicinity of polar mesosphere summer echoes, J. Geophys. Res., 107, 4273, doi:10.1029/2001JD000915, 2002.

Lübken, F.-J., Zecha, M., Höffner, J., and Röttger, J.: Temperatures, polar mesosphere summer echoes, and noctilucent clouds over Spitsbergen $\left(78^{\circ}\right.$ N), J. Geophys. Res., 109, D11203, doi:10.1029/2003JD004247, 2004

Lübken, F.-J., Baumgarten, G., Hildebrand, J., and Schmidlin, F. J.: Simultaneous and co-located wind measurements in the middle atmosphere by lidar and rocket-borne techniques, Atmos. Meas. Tech., 9, 3911-3919, doi:10.5194/amt-9-3911-2016, 2016.

Mlynczak, M. G.: Energetics of the middle atmosphere: Theory and observation requirements, Adv. Space Res., 17, 117-126, 1996.

Mlynczak, M. G. and Solomon, S.: Middle atmosphere heating by exothermic chemical reactions involving odd-hydrogen species, Geophys. Res. Lett., 18, 37-40, doi:10.1029/90GL02672, 1991.

Picone, J. M., Hedin, A. E., Drob, D. P., and Aikin, A. C.: NRLMSISE-00 empirical model of the atmosphere: Statistical comparisons and scientific issues, J. Geophys. Res.-Space, 107, 1468, doi:10.1029/2002JA009430, 2002.

Rapp, M. and Lübken, F.-J.: On the nature of PMSE: Electron diffusion in the vicinity of charged particles revisited, J. Geophys. Res., 108, 8437, doi:10.1029/2002JD002857, 2003.

Rapp, M. and Lübken, F.-J.: Polar mesosphere summer echoes (PMSE): Review of observations and current understanding, Atmos. Chem. Phys., 4, 2601-2633, doi:10.5194/acp-4-2601-2004, 2004.

Rapp, M., Gumbel, J., and Lübken, F.-J.: Absolute density measurements in the middle atmosphere, Ann. Geophys., 19, 571-580, 2001.

Rapp, M., Strelnikov, B., Müllemann, A., Lübken, F.-J., and Fritts, D. C.: Turbulence measurements and implications for gravity wave dissipation during the MacWave/MIDAS rocket program, Geophys. Res. Lett., 31, L24S07, doi:10.1029/2003GL019325, 2004.

Rapp, M., Becker, E., Strelnikov, B., and Lübken, F.-J.: The latitude dependence and probability distribution of polar mesospheric turbulence, Atmos. Chem. Phys. Discuss., 6, 1219912216, doi:10.5194/acpd-6-12199-2006, 2006.

Rapp, M., Strelnikova, I., Latteck, R., Hoffmann, P., Hoppe, U.P., Häggström, I., and Rietveld, M.: Polar Mesosphere Summer Echoes (PMSE) studied at Bragg wavelengths of $2.8 \mathrm{~m}$, $67 \mathrm{~cm}$, and $16 \mathrm{~cm}$, J. Atmos. Solar-Terr. Phys., 70, 947-961, doi:10.1016/j.jastp.2007.11.005, 2008.

Rapp, M., Latteck, R., Stober, G., Hoffmann, P., Singer, W., and Zecha, M.: First three-dimensional observations of polar mesosphere winter echoes: Resolving space-time ambiguity, J. Geophys. Res., 116, A11307, doi:10.1029/2011JA016858, 2011.

Robertson, S., Horányi, M., Knappmiller, S., Sternovsky, Z., Holzworth, R., Shimogawa, M., Friedrich, M., Torkar, K., Gumbel, J., Megner, L., Baumgarten, G., Latteck, R., Rapp, M., Hoppe, U.-P., and Hervig, M. E.: Mass analysis of charged aerosol particles in NLC and PMSE during the ECOMA/MASS campaign, Ann. Geophys., 27, 1213-1232, doi:10.5194/angeo-271213-2009, 2009. 
Scargle, J. D.: Studies in astronomical time series analysis, II - Statistical aspects of spectral analysis of unevenly spaced data, Astrophys. J., 263, 835-853, doi:10.1086/160554, 1982.

She, C. Y., Williams, B. P., Hoffmann, P., Latteck, R., Baumgarten, G., Vance, J. D., Fiedler, J., Acott, P., Fritts, D. C., and Lübken, F.-J.: Simultaneous observation of sodium atoms, NLC and PMSE in the summer mesopause region above ALOMAR, Norway $\left(69^{\circ} \mathrm{N}, 12^{\circ} \mathrm{E}\right)$, J. Atmos. Sol.-Terr. Phys., 68, 93-101, doi:10.1016/j.jastp.2005.08.014, 2006.

Singer, W., Latteck, R., and Holdsworth, D. A.: A new narrow beam Doppler radar at $3 \mathrm{MHz}$ for studies of the highlatitude middle atmosphere, Adv. Space Res., 41, 1488-1494, doi:10.1016/j.asr.2007.10.006, 2008.

Strelnikov, B., Rapp, M., and Lübken, F.-J.: A new technique for the analysis of neutral air density fluctuations measured in situ in the middle atmosphere, Geophys. Res. Lett., 30, 2052, doi:10.1029/2003GL018271, 2003.

Strelnikov, B., Rapp, M., and Lübken, F.-J.: In-situ density measurements in the mesosphere/lower thermosphere region with the TOTAL and CONE instruments, in: An Introduction to Space Instrumentation, edited by: Oyama, K., Terra Publishers, doi:10.5047/isi.2012.001, 2013.

Strelnikova, I. and Rapp, M.: Studies of polar mesosphere summer echoes with the EISCAT VHF and UHF Radars: Information contained in the spectral shape, Adv. Space Res., 45, 247-259, doi:10.1016/j.asr.2009.09.007, 2010.

Strelnikova, I. and Rapp, M.: Majority of PMSE spectral widths at UHF and VHF are compatible with a single scattering mechanism, J. Atmos. Sol.-Terr. Phys., 73, 2142-2152, doi:10.1016/j.jastp.2010.11.025, 2011.

Strelnikova, I. and Rapp, M.: Statistical characteristics of PMWE observations by the EISCAT VHF radar, Ann. Geophys., 31, 359-375, doi:10.5194/angeo-31-359-2013, 2013.
Szewczyk, A.: Mesospheric turbulence: The role in the creation of mesospheric inversion layers and statistical results, $\mathrm{Ph} . \mathrm{D}$. thesis, Universität Rostock, 2015.

Szewczyk, A., Strelnikov, B., Rapp, M., Strelnikova, I., Baumgarten, G., Kaifler, N., Dunker, T., and Hoppe, U.-P.: Simultaneous observations of a Mesospheric Inversion Layer and turbulence during the ECOMA-2010 rocket campaign, Ann. Geophys., 31, 775-785, doi:10.5194/angeo-31-775-2013, 2013.

Tatarskii, V. I.: The Effects of the Turbulent Atmosphere on Wave Propagation, Isr. Program for Sci. Transl., Jerusalem, 1971.

Taylor, M. J., Zhao, Y., Pautet, P.-D., Nicolls, M. J., Collins, R. L., Barker-Tvedtnes, J., Burton, C. D., Thurairajah, B., Reimuller, J., Varney, R. H., Heinselman, C. J., and Mizutani, K.: Coordinated optical and radar image measurements of noctilucent clouds and polar mesospheric summer echoes, J. Atmos. Solar-Terr. Phys., 71, 675-687, doi:10.1016/j.jastp.2008.12.005, 2009.

Thrane, E. V. and Grandal, B.: Observations of fine scale structure in the mesosphere and lower thermosphere, J. Atmos. Terr. Phys., 43, 179-189, 1981.

Thrane, E. V., Andreassen, O., Blix, T., Grandal, B., Brekke, A., Philbrick, C. R., Schmidlin, F. J., Widdel, H. U., von Zahn, U., and Luebken, F. A. J.: Neutral air turbulence in the upper atmosphere observed during the Energy Budget Campaign, J. Atmos. Terr. Phys., 47, 243-264, 1985.

von Zahn, U. and Bremer, J.: Simultaneous and commonvolume observations of noctilucent clouds and polar mesosphere summer echoes, Geophys. Res. Lett., 26, 1521-1524, doi:10.1029/1999GL900206, 1999.

von Zahn, U., Lübken, F.-J., and Puetz, C.: BUGATTI experiments - Mass spectrometric studies of lower thermosphere eddy mixing and turbulence, J. Geophys. Res., 95, 7443-7465, doi:10.1029/JD095iD06p07443, 1990. 